\title{
Closer vein spacing by ectopic expression of nucleotide-binding and leucine-rich repeat proteins in rice leaves
}

\author{
Shuen-Fang Lo ${ }^{1} \oplus$. Jolly Chatterjee ${ }^{2} \cdot$ Akshaya K. Biswal $^{2,3} \cdot$ I.-Lun Liu ${ }^{1} \cdot$ Yu-Pei Chang ${ }^{1} \cdot$ Pei-Jing Chen ${ }^{1}$. \\ Samart Wanchana ${ }^{2} \cdot$ Abigail Elmido-Mabilangan $^{2} \cdot$ Robert A. Nepomuceno $^{4} \cdot$ Anindya Bandyopadhyay $^{5}$. \\ Yue-le Hsing ${ }^{6}$. William Paul Quick ${ }^{2,7}$
}

Received: 14 June 2021 / Accepted: 8 November 2021 / Published online: 27 November 2021

(c) The Author(s) 2021

\begin{abstract}
Key message Elevated expression of nucleotide-binding and leucine-rich repeat proteins led to closer vein spacing and higher vein density in rice leaves.

Abstract To feed the growing global population and mitigate the negative effects of climate change, there is a need to improve the photosynthetic capacity and efficiency of major crops such as rice to enhance grain yield potential. Alterations in internal leaf morphology and cellular architecture are needed to underpin some of these improvements. One of the targets is to generate a "Kranz-like" anatomy in leaves that includes decreased interveinal spacing close to that in $\mathrm{C}_{4}$ plant species. As $\mathrm{C}_{4}$ photosynthesis has evolved from $\mathrm{C}_{3}$ photosynthesis independently in multiple lineages, the genes required to facilitate $\mathrm{C}_{4}$ may already be present in the rice genome. The Taiwan Rice Insertional Mutants (TRIM) population offers the advantage of gain-of-function phenotype trapping, which accelerates the identification of rice gene function. In the present study, we screened the TRIM population to determine the extent to which genetic plasticity can alter vein density (VD) in rice. Close vein spacing mutant 1 (CVS1), identified from a VD screening of approximately 17,000 TRIM lines, conferred heritable high leaf VD. Increased vein number in CVS1 was confirmed to be associated with activated expression of two nucleotide-binding and leucine-rich repeat (NB-LRR) proteins. Overexpression of the two $N B-L R R$ genes individually in rice recapitulates the high VD phenotype, due mainly to reduced interveinal mesophyll cell (M cell) number, length, bulliform cell size and thus interveinal distance. Our studies demonstrate that the trait of high VD in rice can be achieved by elevated expression of NB-LRR proteins limited to no yield penalty.
\end{abstract}

Keywords Close vein spacing (CVS) · Vein density (VD) · Nucleotide-binding and leucine-rich repeat (NB-LRR) protein . Rice · Taiwan Rice Insertional Mutants (TRIM) population

Communicated by Roger Thilmony.

Shun-Fang Lo and William Paul Quick have contributed equally to this work.

Shuen-Fang Lo

jjpipilo@gmail.com

William Paul Quick

w.p.quick@irri.org

1 Biotechnology Center, National Chung Hsing University, Taichung 402, Taiwan, ROC

2 C4 Rice Centre, International Rice Research Institute (IRRI), Los Baños, Philippines

3 Genetic Resources Program, International Maize and Wheat Improvement Center (CIMMYT), Carretera México-Veracruz km. 45, El Batán, Texcoco CP 56237, México
4 National Institute of Molecular Biology and Biotechnology, University of the Philippines (BIOTECH-UPLB), Los Baños 4031, Philippines

5 R\&D Synthetic Biology, Reliance Industries Ltd, Mumbai, India

6 Institute of Plant and Microbial Biology, Academia Sinica, Taipei 115, Taiwan, ROC

7 Department of Animal and Plant Sciences, University of Sheffield, Sheffield, UK 


\section{Introduction}

Rice is a major staple crop that feeds more of the human population than any other crop. The rice yield needs to be significantly increased to secure food supplies in the next few decades. As a $\mathrm{C}_{3}$ plant, rice productivity has reached a ceiling due to its inferior photosynthetic capacity to harvest sunlight, and traditional breeding methods have difficulty achieving a substantial increase in food production. One important strategy to significantly enhance rice productivity is to introduce $\mathrm{C}_{4}$ photosynthesis into rice, as $\mathrm{C}_{4}$ crops have higher photosynthetic capacity, reduced water loss, increased nitrogen $(\mathrm{N})$ use efficiency and higher yields, particularly when grown in hot and dry environments (Furbank et al. 2009; Hibberd et al. 2008). Recent developments in engineering $\mathrm{C}_{4}$ photosynthesis into rice to promote photosynthetic efficiency and yield potential have led to renewed interest in this area (Ermakova et al. 2020; Hibberd et al. 2008; von Caemmerer et al. 2012a, b). However, introducing the $\mathrm{C}_{4}$ trait into rice is a highly challenging project and requires multifaceted modifications to leaf development and metabolism (Kumar and Kellogg 2019; Sedelnikova et al. 2018). The alteration of internal leaf architecture is one of the key prerequisites for establishing the "Kranz anatomy" (Lundgren et al. 2014; Sage et al. 2014).

Close vein spacing with Kranz anatomy in leaves is a distinctive feature of the majority of $\mathrm{C}_{4}$ plant species (Kajala et al. 2011; Kumar and Kellogg 2019). Kranz anatomy is generally composed of a double concentric layer of chlorenchyma cells. The outer mesophyll (M) cells are positioned close to the intercellular air spaces, and the inner specialized bundle sheath (BS) cells surrounding veins are positioned adjacent to $M$ cells in leaves. Such an anatomical arrangement allows the $\mathrm{CO}_{2}$ fixation and decarboxylation steps of photosynthesis to be compartmentalized within the two distinct cell types, $\mathrm{M}$ and BS cells, respectively. An increased frequency of veins per unit leaf area in $\mathrm{C}_{4}$ plants reduces the space between two veins and facilitates the rapid transport of metabolites between M and BS cells (Langdale and Nelson 1991). While the physiology and biochemistry of $C_{4}$ photosynthesis are well known, the genetic basis of Kranz anatomy remains largely unknown.

In addition to being an imperative part of $\mathrm{C}_{4}$ anatomy, vascular tissues function as circulatory organs for supplying water and nutrients to the plant. Vascular tissues are present throughout the plant body from the shoot tip to the root tip (Scarpella and Meijer 2004). Increased VD also has physiological benefits including better hydraulic performance to keep leaves cool and to support photosynthesis in a warm climate. In dicot leaves, veins run in every direction, forming a complicated network, whereas veins are arranged in parallel in monocot leaves and follow basipetal (from tip to base) and acropetal (from base to tip) developmental patterns (Sedelnikova et al. 2018). In monocots, there are three types of longitudinal veins of leaves: the midrib, large veins and small veins (Sack and Scoffoni 2013). Large and small veins are connected by several lateral commissural veins. Molecular and genetic studies on $\mathrm{C}_{4}$ plants, mostly in maize and sorghum, have provided insights into the function, regulation and biological consequences of vein pattern modification in monocots (Kumar and Kellogg 2019). These studies reveal that vein development is regulated by a complex interplay among the hormones auxin and brassinosteroid and the transcription factors SHORTROOT 1 (SHRI)/SCARECROW 1 (SCR1) and INDETERMINATE DOMAIN (IDD) (Kumar and Kellogg 2019; Linh et al. 2018; Sedelnikova et al. 2018). Several mutants with defects or improvements in vein and BS cell development, have been identified in rice (Feldman et al. 2014, 2017; Scarpella et al. 2003; Smillie et al. 2012), which suggests that rice does possess genetic plasticity for altering vein spacing.

A major requirement for engineering Kranz anatomy in $\mathrm{a} \mathrm{C}_{3}$ leaf would be a decrease in the BS-to-M cell ratio, ideally accomplished by increasing the number of veins to effectively increase the BS cell area and decrease the M cell area (Langdale 2011; Sage et al. 2014; Sedelnikova et al. 2018). Since $C_{4}$ photosynthesis occurred via a series of evolutionary modifications from $\mathrm{C}_{3}$ photosynthesis on multiple independent occasions over the last 30 million years (Sage et al. 2011), it is likely that rice already contains all the genes required to induce these changes. Introduction of $\mathrm{C}_{4}$ genes into $\mathrm{C}_{3}$ plants, pyramiding $\mathrm{C}_{4}$-specific genes in one plant, and loss or editing of genes of ancestral $\mathrm{C}_{3}$ genes are feasible approaches to $\mathrm{C}_{4}$ evolution (Clayton et al. 2017; Peng and Zhang 2021; Schuler et al. 2016; Sen et al. 2017; Wang et al. 2016a, b). The rice leaf anatomy is intermediate between these anatomy of most $\mathrm{C}_{3}$ and $\mathrm{C}_{4}$ grasses, indicating that the introduction of Kranz anatomy into rice may not require radical changes (Sage and Sage 2009). However, it is unclear whether the rice genome possesses sufficient "plasticity" with respect to the alteration in leaf morphology that is required to raise photosynthetic rates.

As a first step toward manipulation of rice leaf architecture to phenocopy, a Kranz anatomy into rice, this study set out to identify relevant mutants and genes governing the change in VD in rice by screening a large mutant population. Insertional mutagenesis, whereby T-DNA vectors containing multimeric CaMV35S enhancers are inserted randomly into the rice genome, can be used to activate gene expression, thereby leading to gain-of-function mutations (Hsing et al. 2007; Lo et al. 2016). Screening these mutant populations will facilitate the identification of the missing genetic components regulating the $\mathrm{C}_{4} \mathrm{Kranz}$ anatomy.

Members of the nucleotide-binding and leucine-rich repeat (NB-LRR) protein family have been found to serve 
as crucial regulators of inflammatory and innate immune responses in animals and plants, respectively (Ye and Ting 2008). The majority of plant disease resistance (R) proteins conferring resistance to bacterial, fungal, oomycete or viral pathogens encode proteins belonging to the NB-LRR protein family (Dangl and Jones 2001). The central NB domain has a role in signal transduction mediated by nucleotide phosphorylation and is the most conserved part of the gene; the C-terminal LRR domain is generally required for specific recognition of pathogen effectors; and the N-terminal coiled-coil (CC) domain is present only in NB-LRRs from monocots involved in signaling and likely pathogen recognition (Takken and Goverse 2012). The Arabidopsis and rice genomes contain 150 and $480 N B-L R R$ genes, respectively (Yang et al. 2006) and to date, most of them have not been studied. Ectopic expression of several $C C-N B-L R R$ and $N B$ $L R R$ genes isolated from Arabidopsis, maize and rice can confer resistance to blast disease caused by Magnaporthe oryzae in rice (Li et al. 2019; Ma et al. 2015; Singh et al. 2020; Xu et al. 2018), indicating the functional conservation of NB-LRRs against pathogens.

We screened a total of approximately 17,000 TRIM lines for alterations in vein patterning and leaf cellular architecture. Using a simple, high-throughput screen for leaf VD, we identified mutant lines with a heritable increase in the number of veins per unit leaf width due to a reduction in the interveinal distance, a phenotype designated as close vein spacing (CVS). Part of the TRIM population was screened previously along with rice variety IR64 deletion mutants to determine the range of VD in rice, although the causal genes were never identified (Feldman et al. 2014). In the present study, CVS mutants from the TRIM population were identified and characterized in terms of their potential to engineer $\mathrm{C}_{4}$ leaf anatomy in rice. We further demonstrated that ectopic expression of each of two $N B-L R R$ and $C C-N B-L R R$ genes makes the interveinal distance closer by reducing the interveinal $\mathrm{M}$ cell number, $\mathrm{M}$ cell length and bulliform cell size, leading to increased VD in rice leaves. The increase in VD in G2-NB-LRR and G7-NB-LRR transgenic plants was highest at the seedling stage and became insignificant when the plants entered the reproductive stage, which avoided adverse effects on grain yield. To the best of our knowledge, this is the first report on the function of $N B-L R R$ genes in the regulation of leaf internal architecture.

\section{Materials and methods}

\section{Plant materials}

For gene expression analysis and seedling morphology characterization, seeds were surface sterilized in $2.5 \%$ sodium hypochlorite and germinated on half-strength MS agar medium (Murashige and Skoog Basal Medium with Vitamins; Phyto Technology Laboratories $\left.{ }^{\circledR}\right)$ (Murashige and Skoog 1962) at $28{ }^{\circ} \mathrm{C}$ with $16 \mathrm{~h}$ of light and $8 \mathrm{~h}$ of darkness for 10-20 days. For yield analysis and vein spacing evaluation, plants were cultivated at the National ChungHsing University experimental farm under natural growing conditions.

\section{Screening for leaf CVS mutants}

A total of $17,324 T_{1}$ generation lines with 12 plants per line were screened from the Taiwan Rice Insertional Mutants (TRIM) population (http://rice.sinica.edu.tw/fgb2/gbrowse/ TRIM_gb/) in 8 field experiments at either National Chung Hsing University, Taiwan $\left(25.0330^{\circ} \mathrm{N}, 121.5654^{\circ} \mathrm{E}\right)$ or the International Rice Research Institute (IRRI) in the Philippines (14 ${ }^{\circ} 9^{\prime} 53.58^{\prime \prime} \mathrm{N} 121^{\circ} 15^{\prime} 32.19^{\prime \prime} \mathrm{E}$ ) from 2009 to 2012 (Supplementary Table S1). The population used T-DNA pTAG8 containing an enhancer -tetramer and selectable markers (Supplementary Fig. S1), which function in gene trapping, knockout and activation tagging (Hsing et al. 2007; Lo et al. 2016) in the genetic background of Oryza sativa cv Tainung 67 (TNG67).

Sterilized seeds were germinated on sterile damp filter paper in Petri dishes in the dark at $30{ }^{\circ} \mathrm{C}$ for 3 days, followed by 2 days in the light at the same temperature. Seedlings were transplanted into pots maintained in a screen house or in the field. Pots were filled with soil from the IRRI upland farm mixed with $25 \%$ coco-coir and $0.4 \mathrm{~g} / \mathrm{L}$ Osmocote Plus 15-9-12 (The Scotts Company Ltd., Thorne, UK). One of the high VD candidate mutants, M0104656, was grown in successive generations $\left(T_{2}-T_{7}\right)$ in pots with soil in the screen house at IRRI.

Leaf VD is defined as the total number of veins per $\mathrm{mm}$ leaf width. A 5-cm-long piece of the mid-section of the fully expanded fifth leaf was sampled for VD quantification. VD was counted in a 1-mm field of view at four locations on both the left- and right-hand sides of the leaf using a Meade ReadView Portable Microscope (Meade Instruments Corp. CA, USA). For experiments conducted in Taiwan, leaf samples were fixed in formaldehyde alcohol fixatives and imported to IRRI. The VD of each line was counted in ImageJ and recorded in a Microsoft Excel Workbook (Microsoft Corp, USA). Any mutant plant found to have $>7.0$ veins in a $1-\mathrm{mm}$ field of view was considered to have a CVS phenotype and was subjected to detailed microscopic examination. Mutant lines with a heritable CVS phenotype were further characterized in successive generations.

\section{Leaf anatomy}

Leaves were examined using cleared sections, thin sections or fluorescence images to detect chloroplast positions. 
Fluorescence images of leaf cross-sections were captured using fresh leaves to detect chloroplast positions as described (Chatterjee et al. 2016). Leaves were fixed in FAA solution $[3.7 \%(\mathrm{v} / \mathrm{v})$ formaldehyde, $5 \%(\mathrm{v} / \mathrm{v})$ acetic acid, and $50 \%$ ethanol] and were later used for preparation of cleared sections. Leaf sections were cleared as described (Lux et al. 2005 ) and stained with $0.05 \%$ toluidine blue.

For a detailed characterization of leaf anatomy, thin sections were prepared from leaves fixed in a $2.5 \%$ glutaraldehyde solution as described (Chatterjee et al. 2016). Leaf discs were dehydrated in a graded ethanol series (McKown and Dengler 2007) and embedded in Spurr's resin (Spurr 1969). Samples were sectioned using a Sorvall MT2-B Ultramicrotome (DuPont-Instruments-Sorvall, Newtown, CT, USA) and stained in $0.05 \%$ toluidene blue. All sections were viewed under an OLYMPUS BX51 or motorized BX61 and/or BX63 microscope (Olympus Optical, Tokyo, Japan). Leaf section images were acquired with an Olympus DP71 digital documentation system attached to the microscope.

\section{Image analysis}

All images of leaf anatomy were analyzed with Olympus cellSens software (www.olympus-lifescience.com/en/softw are/cellsens/) and ImageJ software v.1.43 (https://imagej.nih. gov/ij/index.html) to determine leaf VD, leaf thickness $(\mu \mathrm{m})$, interveinal distance $(\mu \mathrm{m}), M$ cell length $(\mu \mathrm{m}), \mathrm{M}$ cell number between two minor veins, $\mathrm{M}$ cell total area $\left(\mathrm{mm}^{2}\right), \mathrm{M}$ cell lobing (the ratio of the actual cell perimeter to the minimum circumference of the cell), BS cell number, BS cell area $\left(\mu \mathrm{m}^{2}\right)$, vein area $\left(\mu \mathrm{m}^{2}\right)$ and bulliform cell area $\left(\mu \mathrm{m}^{2}\right)$. Measurements were made only at the middle portion of transverse leaf sections. M cell length and lobing were examined as described (Chatterjee et al. 2016; Giuliani et al. 2013). Measurements were made on 25 random segments from 3 sections per leaf and 3 leaves from 3 plants per line. Leaf width $(\mathrm{mm})$ was measured prior to leaf sectioning.

\section{Gas exchange measurements}

Leaf gas exchange measurements were made at IRRI (mean atmospheric pressure of $94.8 \mathrm{kPa}$ ) using a Li-6400XT infrared gas exchange analyzer (LI-COR Biosciences, Lincoln, NE, USA) fitted with a standard $2 \times 3 \mathrm{~cm}$ leaf chamber and 6400-02 B light source. Measurements were made at a constant airflow rate of $400 \mu \mathrm{mol} \mathrm{s}{ }^{-1}$, leaf temperature of $30{ }^{\circ} \mathrm{C}$, leaf-to-air vapor deficit between 1.0 and $1.5 \mathrm{kPa}$ and relative humidity of 60-65\%. Data were acquired between 0800 and $1300 \mathrm{~h}$ in a room with the air temperature maintained at approximately $30{ }^{\circ} \mathrm{C}$. Measurements were made on the mid-portion of the leaf blade of three fully expanded leaves formed during the tillering stage from two plants. Leaves were acclimated in the cuvette for approximately $30 \mathrm{~min}$ before measurements were made. The response curves of the net rate of assimilation $\left(A, \mu \mathrm{mol} \mathrm{m}{ }^{-2} \mathrm{~s}^{-1}\right)$ to changing intercellular $\mathrm{CO}_{2}$ concentration $\left(\mathrm{Ci}, \mu \mathrm{mol} \mathrm{CO} \mathrm{Col}^{-1}\right)$ were acquired by increasing the $\mathrm{Ca}\left(\mathrm{CO}_{2}\right.$ concentration in the cuvette) from 20 to $1500 \mu \mathrm{mol} \mathrm{CO} \mathrm{Col} \mathrm{air}^{-1}$ at a photosynthetic photon flux density (PPFD) of $1000 \mu$ mol photon $\mathrm{m}^{-2} \mathrm{~s}^{-1}$. Light response curves were acquired by decreasing the PPFD from 2000 to $0 \mu \mathrm{mol}$ photons $\mathrm{m}^{-2} \mathrm{~s}^{-1}$ at $\mathrm{Ca}$ $400 \mu \mathrm{mol} \mathrm{CO} \mathrm{mol}^{-1}$. The $\mathrm{CO}_{2}$ compensation point $(\Gamma)$ and maximum carboxylation efficiency $(C E)$ were calculated from the intercept (Vogan et al. 2007) and slope (Wang et al. 2006) of the $\mathrm{CO}_{2}$ response curves. The quantum yield for $\mathrm{CO}_{2}$ assimilation $(\varphi)$ was calculated from the slope of the light response curves (Farquhar and Wong 1984). The maximum carboxylation rate allowed by Rubisco $\left(V_{\mathrm{cmax}}\right)$, rate of photosynthetic electron transport based on NADPH requirements $(J)$, triose phosphate use $(T P U)$, daytime respiration $\left(R_{\mathrm{d}}\right)$ and mesophyll conductance $\left(g_{\mathrm{m}}\right)$ were calculated using the curve fitting tool as described (Sharkey et al. 2007).

\section{T-DNA flanking sequence analysis}

Genomic DNA of mutants was extracted with CTAB extraction buffer as described (Doyle 1987). T-DNA flanking sequences were recovered using a built-in plasmid rescue system (Upadhyaya et al. 2002) and analyzed with an ABI Prism 3100 DNA sequencer (Applied Biosystems) using DNA sequences $100 \mathrm{bp}$ upstream of the T-DNA right border (Hsing et al. 2007) as an RB primer (Supplementary Table S2). T-DNA flanking sequences were blasted against the Rice Annotation Project Database (RAP-DB, https:// rapdb.dna.affrc.go.jp/viewer/gbrowse/irgsp1/) or MSU Rice Genome Annotation Project 7 (RGAP 7, http://rice. plantbiology.msu.edu/) (Kawahara et al. 2013) for identification of the T-DNA insertion site. Gene loci within a 40-kb region up- and downstream of the T-DNA insertion site were obtained from the RAP-DB or RGAP 7 database.

For analysis of the T-DNA copy number in CVS1 and the T-DNA insertion site that associates with the CVS phenotype, genomic DNA was extracted from leaves of CVS1, digested with Sph I, and subjected to DNA gel blot analysis using the hygromycin phosphotransferase gene $(\mathrm{Hyg})$ as a probe.

\section{Quantitative RT-PCR}

Total RNA was extracted from the first fully expanded leaf of the main tiller of two plants per line using TRIzol Reagent (Thermo Fisher Scientific, USA). Real-time polymerase chain reaction (RT-PCR) analyses were conducted as described (Lo et al. 2008). 


\section{Statistical analysis}

All statistical analyses were performed in STAR, an R-based software developed by IRRI or with Student's $t$ test using SigmaPlot software (version 11.0, Systat Software, Inc.). All results are presented as the mean \pm SE. Significance levels were determined with the $t$ test: $* P<0.05, * * P<0.01$, $* * * P<0.001$

\section{Transgenic rice overexpressing NB-LRR}

Full-length cDNAs of genes flanking the T-DNA insertion site in CVS1 were PCR-amplified from rice (TNG67) mRNA based on their putative open reading frames annotated with the RGAP 7 database (Kawahara et al. 2013). cDNAs were ligated into the pGEM®-T Easy cloning vector (Promega), and their sequences were confirmed by DNA sequencing analysis. Plasmid pAHC18 (Bruce et al. 1989), derived from plasmid $p U C 18$, contains the maize ubiquitin gene (Ubi) promoter and nopaline synthase gene (Nos) terminator. cDNAs were excised from the pGEM-T Easy vector and ligated into a site between the Ubi promoter and Nos terminator in plasmid pAHC18. Plasmids containing Ubidriven cDNA of various genes were individually linearized with HindIII and inserted into the same site in pCAMBIA1301 (Hajdukiewicz et al. 1994). The resulting binary vectors were transferred into Agrobacterium tumefaciens strain EHA105. Calli were induced from immature rice seeds of Oryza sativa cv Tainung 67 for rice transformation. The calli were cocultured with $A$. tumefaciens with binary vectors. The $T_{0}$ transgenic plants were regenerated and screened from calli following the method described (Chen et al. 2002).

To calculate the vein density of transgenic plants in various generations, we screened out the segregated wild type of transgenic plants. All analyzed plants were heterozygous/ homozygous, and the uppermost fully expanded leaf was collected for all VD data calculations.

\section{Phylogenetic analysis of NB-LRRs}

Phylogenetic analysis of NB-LRRs in rice and other plant species was performed with full-length amino acid sequences by MEGA X software (Kumar et al. 2018) using the neighbor-joining method (Saitou and Nei 1987). The evolutionary distance was computed using the Poisson correction method (Zuckerkandl and Pauling 1965) and is reported as the number of amino acid substitutions per site. All ambiguous positions were removed for each sequence pair (pairwise deletion option). The accession numbers of the genes are listed in Supplementary Table S5.

\section{Primers}

All primers used for DNA sequencing, quantitative RT-PCR and genome typing are provided in Supplementary Table S2.

\section{Results}

\section{Screening and identification of the CVS1 mutant}

The VD of wild-type (WT) plants ranged between 4 and 6.5 veins per mm of leaf width, with $84 \%$ of the population having a VD of either 4.5 or 5.0 veins per mm (Fig. 1a). The range of VD was broader in the mutant population, numbering between 2.5 and 10 veins per mm (Fig. 1a). Approximately, $0.32 \%$ of the mutant population had a VD lower than 4 veins per $\mathrm{mm}$, and only $0.05 \%$ had a VD of 7 or more veins per mm leaf width.

The threshold VD for a mutant to be considered as a CVS candidate was set at 7 veins per mm leaf width, which is above the maximum VD of the WT population. From a total of 17,324 TRIM lines screened (Supplementary Table S1),
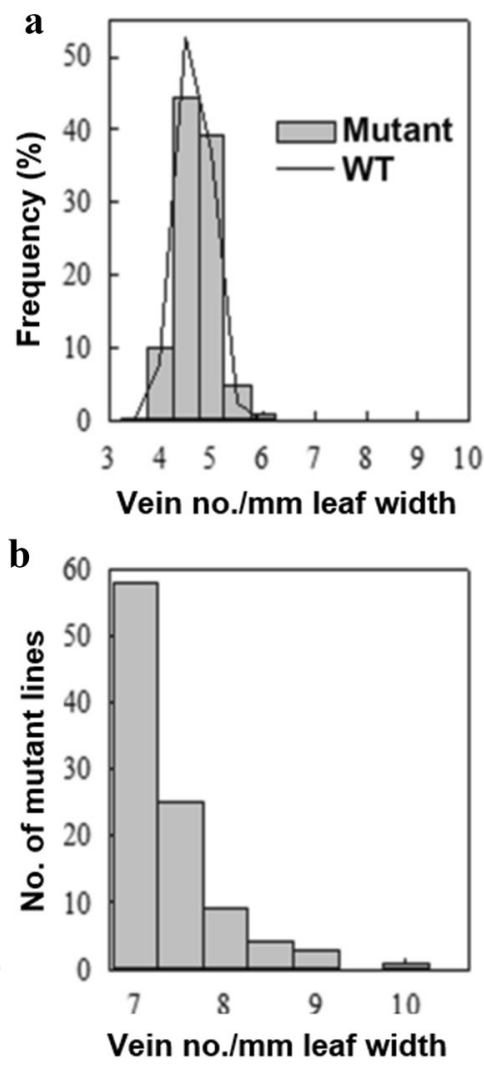

Fig. 1 VD screening of the TRIM population for high VD mutants and frequency of VD distribution in mutants. a Frequency of VD (vein number per mm leaf width) distribution in WT $(n=3139)$ and mutant lines $(n=17,324)$. b Number of mutant lines $(n=100)$ with VD equal to or greater than 7 veins per mm leaf width 
a
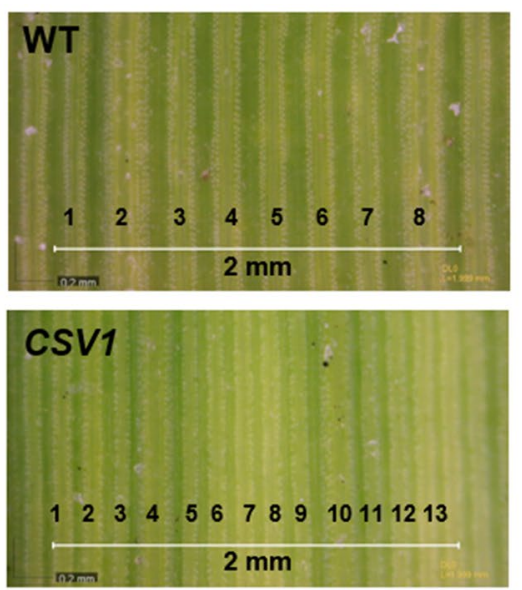

b

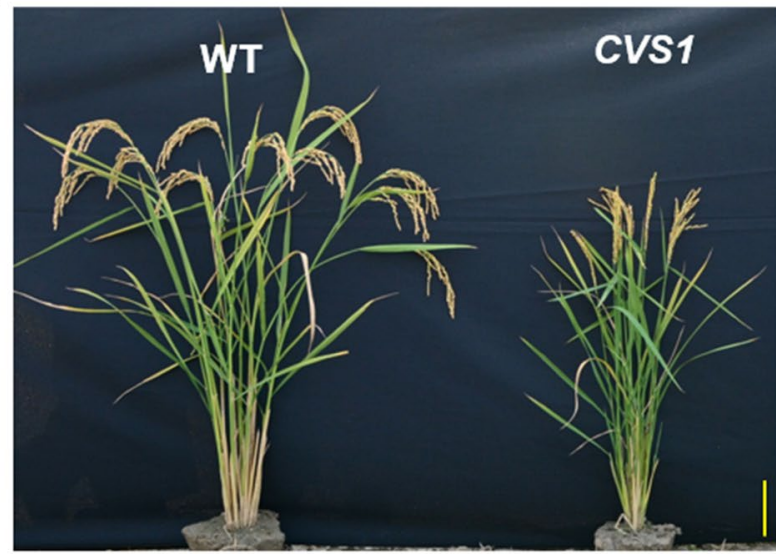

Fig. 2 VD is increased but plant height is reduced in CVS1. a Representative images of leaf VD. Images were captured from fully expanded leaves of WT and CVS1 plants of the $T_{2}$ generation. The number on leaves indicates the vein number per $2 \mathrm{~mm}$ leaf width, with 8 veins in WT and 13 veins in CVS1. b Phenotypes of representative WT and CVS1 plants of the $T_{4}$ generation. The plant age was 120 days after sowing. Scale $b a r=10 \mathrm{~cm}$
100 candidates were identified as having the CVS phenotype (Fig. 1b). A total of 49 candidate lines were prioritized for secondary screening by selecting only those with the CVS phenotype on both sides of the leaf. Of these, 23 mutant lines could not be rescreened, as the CVS phenotype was associated with seed sterility or was lethal. Only 7 of the 26 remaining lines showed a heritable phenotype in the $T_{2}$ generation, and only 3 in the $T_{3}$ generation exhibited the phenotype (Supplementary Table S3). Due to low yield in one of the three mutant lines (M0110124), only two CVS mutants, M0104656 (CVS1) and M0105588 (CVS2), were screened beyond the $T_{4}$ generation. $C V S 1$ was further characterized in this study.

In the $T_{1}$ generation of $C V S 1,2$ out of 12 progenies exhibited the CVS phenotype, with an average VD of $7.00 \pm 0.01$ (Supplementary Fig. S2), which is consistent with the photo showing that the VD was 8 in WT and 13.5 in CVS1 within a $2 \mathrm{~mm}$ leaf width (Fig. 2a). As VD was considered likely to exhibit phenotypic plasticity in response to environmental changes, the progeny of this mutant were advanced to successive generations through single seed decent by selecting only progenies with the highest VD in each generation until a predominant CVS phenotype was obtained (Supplementary Fig. S3). We did not observe a clear Mendelian inheritance in the early generations, which was attributed to the small population size screened and the lack of colinking information on T-DNA insertion and copy number in CVSI. However, by the $T_{6}$ generation, progenies of $C V S 1$ could be clearly distinguished from the WT (Supplementary Fig. S3). CVSI also has a semidwarf stature and low grain yield phenotype compared to WT (Fig. 2b, Supplementary Fig. S6).
Table 1 Comparison of leaf anatomy between WT and CVS1

\begin{tabular}{llllc}
\hline Parameter & Unit & WT & CVS1 & CVS1/WT (\%) \\
\hline Vein density & Count per mm & $\mathbf{5 . 1 7} \pm \mathbf{0 . 1 7}$ & $\mathbf{6 . 9 7} \pm \mathbf{0 . 2 4 * *}$ & $\mathbf{1 3 5}$ \\
Leaf width & $\mathrm{cm}$ & $0.83 \pm 0.03$ & $0.52 \pm 0.06^{* * *}$ & 63 \\
Leaf thickness & $\mu \mathrm{m}$ & $95.19 \pm 1.81$ & $96.86 \pm 3.20$ & 102 \\
Interveinal distance & $\mu \mathrm{m}$ & $185.78 \pm 2.75$ & $126.16 \pm 3.44^{* * *}$ & 68 \\
M cell length & $\mu \mathrm{m}$ & $24.61 \pm 1.02$ & $18.09 \pm 0.51^{* *}$ & 74 \\
BS cell number & count & $10.47 \pm 0.54$ & $10.24 \pm 0.30$ & 98 \\
BS cell area & $\mu \mathrm{m}^{2}$ & $112.41 \pm 11.42$ & $97.84 \pm 5.17$ & 87 \\
Vein area & $\mu \mathrm{m}^{2}$ & $779.19 \pm 64.22$ & $723.53 \pm 62.77$ & 93 \\
Bulliform cell area & $\mu \mathrm{m}^{2}$ & $2117.42 \pm 54.38$ & $1278.16 \pm 38.63^{* * *}$ & 60 \\
\hline
\end{tabular}

Values are the means \pm SE of measurements from 54 transverse leaf section images made on the left and right side of the leaf from three leaves of three $T_{6}$ generation plants per line. *Represents a significant difference compared to WT, $P \leq 0.05$, $* * \mathrm{P} \leq 0.01$ and $* * * P \leq 0.001$. Bold and italics fonts indicate significant increases and decreases in value, respectively 


\section{Interveinal distance is reduced and $M$ cell architecture is altered in CVS1}

We found that compared with WT, vein number was increased by $2 \sim 3$ per mm leaf width $(\sim 35 \%)$, and interveinal distance was reduced by $32 \%$ in CVSI (Fig. 2a, Table 1). There was no change in leaf thickness, BS cell number and area, or vein area. The average leaf width and bulliform cell area of CVS1 were reduced by 37 and $40 \%$, respectively (Table 1). Leaf VD was negatively correlated with leaf width in both WT and CVS1 (Supplementary Fig. S4).

The CVS phenotype in CVS1 was found to be associated with abnormal $\mathrm{M}$ cell development. There was a reduction in the length (by 26\%) and total area of M cells (by 30-50\%) (Table 1, Fig. 3a, b) in CVS1. A marked decline in M cell lobing in CVS1 was also detected (Fig. 3a), with an average M cell lobing of $1.1 \pm 0.01$ in CVS1 compared to $1.4 \pm 0.04$ in WT (Fig. 3b), which is accompanied by the abundance and positioning of chloroplasts (Fig. 3c). There was an almost complete absence of chloroplasts from $\mathrm{M}$ cells in the middle of leaves and an aggregation of chloroplasts around the periphery of $\mathrm{M}$ cells on both abaxial and adaxial leaf surfaces, suggesting that the development of chloroplasts was inhibited in CVSI (Fig. 3c).

\section{Photosynthetic performance is decreased in CVS1}

The rates of $\mathrm{CO}_{2}$ assimilation $(A)$ were decreased in $C V S 1$ at all intercellular $\mathrm{CO}_{2}$ concentrations ( $\mathrm{Ci}$ ) (Fig. 4a) and stomatal conductance $\left(g_{\mathrm{s}}\right)$ (Fig. 4c, d), reflecting a statistically significant lower $C E$, higher $R_{\mathrm{d}}$ and lower $g_{\mathrm{m}}$ (Table 2). There was no apparent difference in $V_{\text {cmax }}, J$ or TPU and no consistent statistically significant difference in $\Gamma$. The response of $A$ to PPFD was also altered (Fig. 4b), with saturation of $A$ occurring much earlier than normal at $750 \mu \mathrm{mol} \mathrm{m}^{-2} \mathrm{~s}^{-1}$ in CVS1 compared to $>2000 \mu \mathrm{mol} \mathrm{m} \mathrm{s}^{-1}$ in WT. The quantum efficiency of $\mathrm{CO}_{2}$ assimilation in $C V S I$ was also lower than the quantum efficiency of $\mathrm{CO}_{2}$ assimilation in WT (Table 2).
Fig. 3 Interveinal spacing is reduced and $\mathrm{M}$ cell architecture is altered in CVS1. a Light micrographs illustrating transverse sections of $M$ cells in the leaves of WT and CVS1 plants of the $T_{2}$ generation. $\mathrm{M}$ cell size was reduced in CVS1. Arrow heads indicate reduced $\mathrm{M}$ cell lobing in CVS1. Interveinal $M$ cells are numbered. Scale bar $=50 \mu \mathrm{m}$. b Quantification of $\mathrm{M}$ cell area and lobing in leaves of WT and CVS1. Values are the average \pm SE of measurements from a minimum of 25 random segments from 3 sections per leaf. Three leaves from three WT and $C V S 1$ plants of the $T_{4}$ generation were measured. Asterisks denote significant differences compared to the WT $(P<0.005)$. c Chloroplast abundance in M cells in CVS1. Representative fluorescent images show transverse leaf sections of WT and CVS1 plants of the $T_{6}$ generation, depicting the red autofluorescence of chloroplasts. Arrows indicate reduced chloroplast content in M cells of CVS1. $\mathrm{M}=$ cells. $\mathrm{B}=$ Bulliform cells. Circles indicate vascular bundles. Magnification 200×. Scale bar $=20 \mu \mathrm{m}$ a

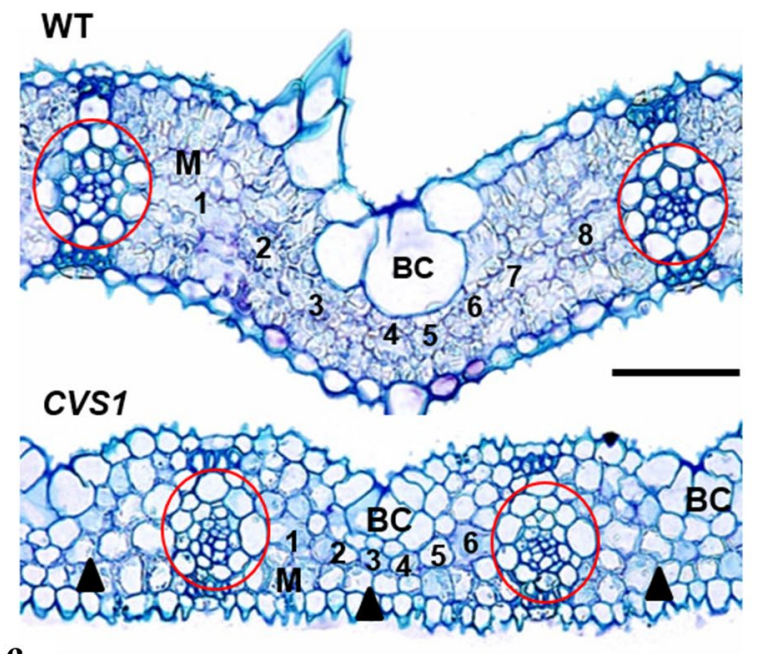

c
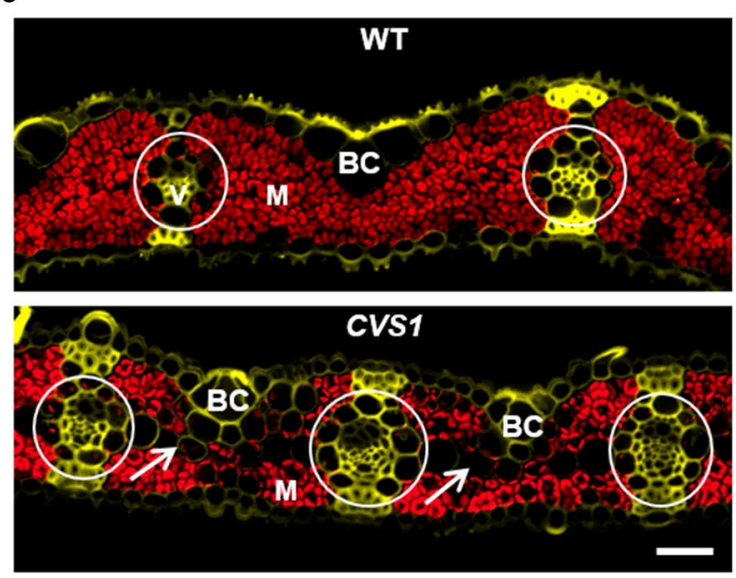

b

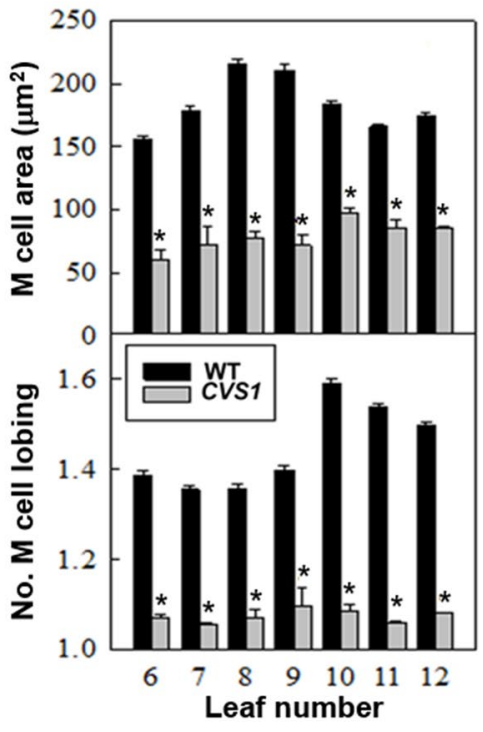



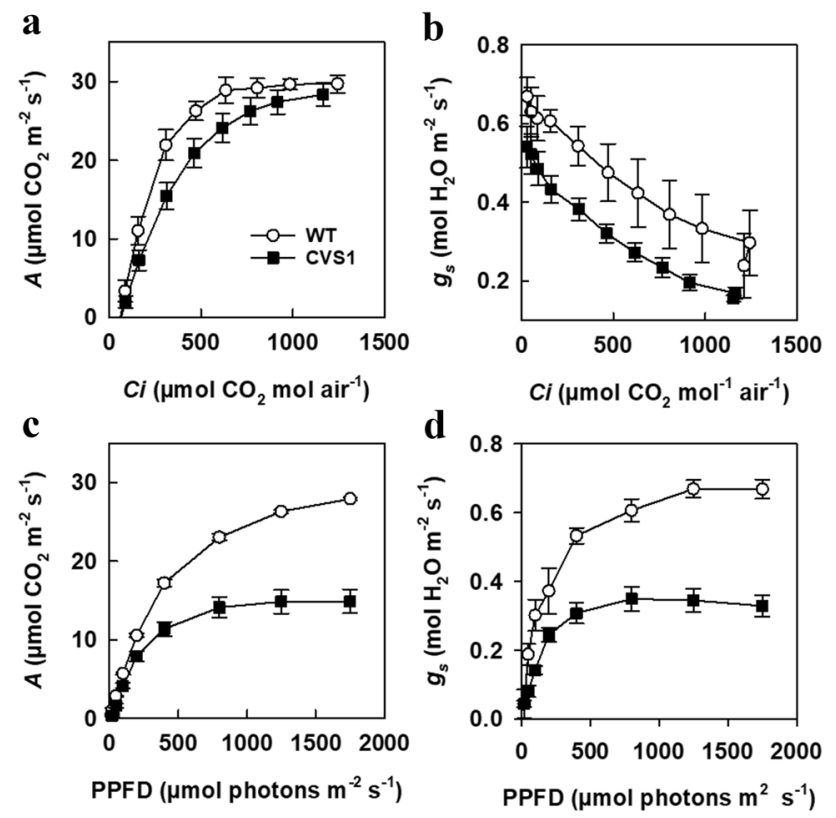

Fig. 4 Photosynthetic performance is decreased in CVS1. a $\mathrm{CO}_{2}$ assimilation (A) and b conductance (gs) of WT and CVS1 plants of the $T_{5}$ generation and mutant $\mathbf{c}$ intercellular $\mathrm{CO}_{2}$ concentration ( $\mathrm{C} i$; [left panel]) and d photosynthetic flux density (PPFD, [right panel]). Measurements were made at a leaf temperature of $30{ }^{\circ} \mathrm{C}$ and either a light intensity of $2,000 \mu \mathrm{mol}$ photons $\mathrm{m}^{-2} \mathrm{~s}^{-1}$ or a $\mathrm{Ca}$ of $400 \mu \mathrm{mol} \mathrm{mol}{ }^{-1} \mathrm{CO}_{2}$. Values represent the mean $\pm \mathrm{SE}$ of three leaves per plant and three plants per line

\section{Identification of T-DNA insertion sites in CVS1}

Southern blot analysis of CVS1 showed that two copies of T-DNA were inserted in the CVS1 genome (Fig. 5a). The 2 T-DNA insertion sites were blasted to chromosomes 9 (locus 8,282,951 bp) and 12 (locus 22,42,9649 bp). The CVS and semidwarf phenotypes cosegregated with the T-DNA insertion on chromosome 9 but not the insertion on chromosome 12 (Fig. 5b-d) based on genotyping of homozygous lines (Fig. 5c, d). A more extensive genotyping analysis of $T_{5}$ and $T_{6}$ generations showed that both heterozygous and homozygous progenies possessed HVD morphology, which demonstrated that the CVS phenotype is likely due to a dominant mutation in CVS1 (Fig. S5). Another TRIM line, M0125469, is a neighboring mutant of CVS1 chromosome 9 (M0104656), as it contains a T-DNA inserted at a position $22 \mathrm{~kb}$ upstream of the T-DNA insertion site on chromosome 9 of CVSI (Fig. 5e). M0125469 exhibited a slightly higher VD than WT (Fig. 5f).

\section{Genes activated in CVS1 and the allelic mutant M125469}

A total of 7 genes (designated G1-G7) were predicted to be present within a $70 \mathrm{~kb}$ region up- and downstream of the T-DNA insertion site on chromosome 9 of CVS1 (Fig. 6a). These genes include hypothetical and NB-LRR proteins (Supplementary Table S4). Semiquantitative RT-PCR showed that only $G 4$ was expressed in WT leaves under normal growth conditions. $G 5$ is a putative transposon protein; thus, its expression was not analyzed. Expression of the $G 1, G 2, G 6$ and $G 7$ genes was activated in CVS1, expression of the $G 4$ gene was activated only in the allelic mutant M0125469 but not in CVS1, and expression of $G 3$ was not detected in any line (Fig. 6b). G6 was not expressed in M0125469. T-DNA was inserted at a position $16 \mathrm{bp}$ downstream of the stop codon within the 3' untranslated region (3'UTR) of G4. We excluded G4 from further analysis, as it was activated only in the allelic mutant M125469 and did not lead to a higher VD phenotype in CVSI.

\section{The CVS phenotype is recapitulated by overexpression of $N B-L R R s$ in transgenic rice}

$G 1, G 2, G 6$ and $G 7$ were individually overexpressed in transgenic rice under the control of the Ubi promoter. The mRNA of these genes accumulated into much higher levels in transgenic lines than in WT (Supplementary Fig. S7a-d). We found that only transgenic plants carrying the Ubi:G2-NB-LRR and Ubi:G7-NB-LRR constructs displayed the CVS phenotype; however, the increase in VD was not as high as that the increase in VD in CVS1 (Fig. 7a,

Table 2 Photosynthetic parameters of the wild-type (WT) and mutant CVS1

\begin{tabular}{|c|c|c|c|c|c|c|c|c|}
\hline & $\begin{array}{l}\varphi \\
\mu \mathrm{mol} \mathrm{CO}_{2} \mu \mathrm{mol}^{-1} \\
\text { quanta }\end{array}$ & $\begin{array}{l}\Gamma \\
\mu \mathrm{mol} \mathrm{CO}\end{array}$ & $\begin{array}{l}C E \\
\mu \mathrm{mol} \mathrm{CO} \\
\mathrm{m}^{-2} \mathrm{~s}^{-1} \mu \mathrm{mol} \\
\mathrm{CO} 2 \mathrm{~mol}^{-1}\end{array}$ & 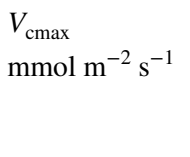 & 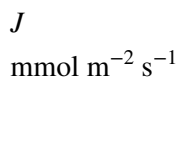 & $\begin{array}{l}T P U \\
\mathrm{mmol} \mathrm{m}^{-2} \mathrm{~s}^{-1}\end{array}$ & $\begin{array}{l}R_{d} \\
\mathrm{mmol} \mathrm{m}^{-2} \mathrm{~s}^{-1}\end{array}$ & 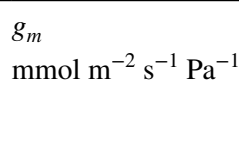 \\
\hline WT & $0.053 \pm 0.000$ & $59.5 \pm 1.90$ & $0.120 \pm 0.009$ & $131.02 \pm 2.91$ & $127.69 \pm 4.74$ & $9.33 \pm 0.18$ & $2.29 \pm 0.26$ & $3.30 \pm 0.18$ \\
\hline CVS1 & $0.042 \pm 0.003$ & $65.0 \pm 3.20$ & $0.080 \pm 0.008 * * *$ & $136.72 \pm 9.91$ & $124.32 \pm 7.59$ & $9.02 \pm 0.47$ & $4.05 \pm 0.41 * * *$ & $0.91 * * * \pm 0.13 * * *$ \\
\hline
\end{tabular}

Values are the means $\pm \mathrm{SE}$ of one leaf from 3 plants per line. ***represents a significant difference compared to WT $(P \leq 0.005) . \varphi$ quantum yield for $\mathrm{CO}_{2}$ assimilation, $\Gamma \mathrm{CO}_{2}$ compensation point, $C E$ maximum carboxylation efficiency, $V_{\text {cmax }}$ maximum carboxylation rate allowed by Rubisco, $J$ rate of photosynthetic electron transport (based on NADPH requirements), TPU triose phosphate use, $R_{d}$ daytime respiration, $g_{m}$ mesophyll conductance 
a

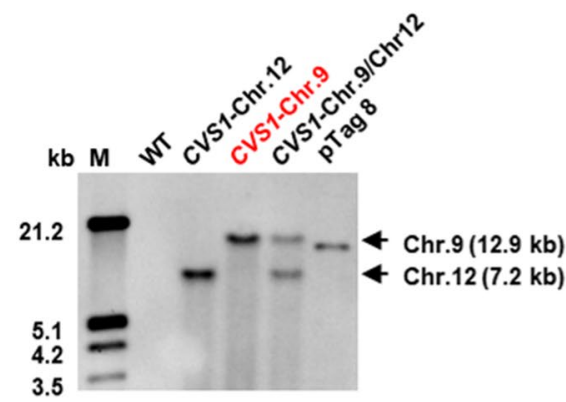

c

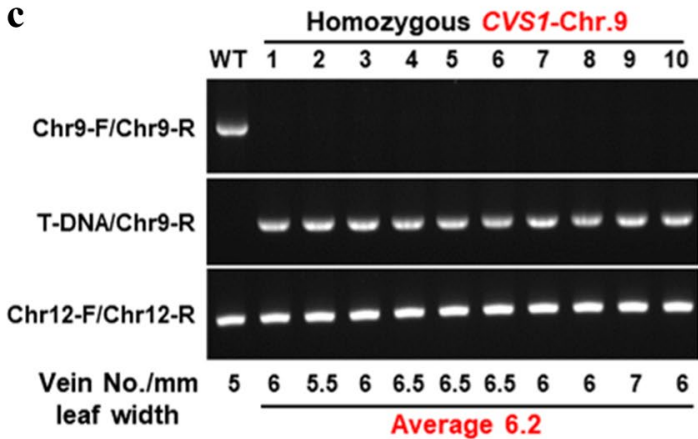

d

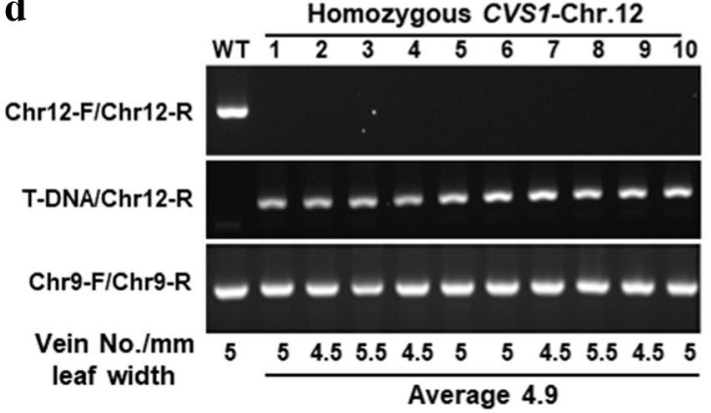

Fig. 5 One of two T-DNAs inserted in the genome of CVS1 is associated with the CVS phenotype. a DNA gel blot analysis using Hyg in the T-DNA as a probe. Plasimd pTaq 8 was used as a positive control. M: molecular weight marker in kb. Only the T-DNA inserted on chromosome 9 was associated with the CVS phenotype. b Phenotypes of two segregated TRIM lines, CVS1-Chr.9 and CVS1-Chr.12, which each carry a T-DNA insertion on chromosomes 9 and 12, respectively. c Genotyping and phenotyping of homozygous CVS1-Chr.9. Three primer sets, Chr9-F and Chr9-R, T-DNA and Chr9-R, and Chr12-F and Chr12-R, amplified WT and T-DNA-inserted genomic DNA on chromosome 9 and WT genomic DNA of the T-DNA inser-

Supplementary Fig. S7e). We further screened the increase in VD at different stages and found that the increase in VD was highest at the earlier seedling stage, with $12 \%$ and $13 \%$ higher VD in G2-NB-LRR and G7-NB-LRR than in $\mathrm{WT}$, respectively. As transgenic plants grow and mature, the increase in VD decreases from 12 and $13 \%$ to $4 \%$. (Fig. 7a, Tables 3, 4). The $T_{3}$ transgenic plants overexpressing G2-NB-LRR and G7-NB-LRR possessed slightly higher chlorophyll content and photosynthesis rate (the value of photosynthesis rate was not statistically significant), and

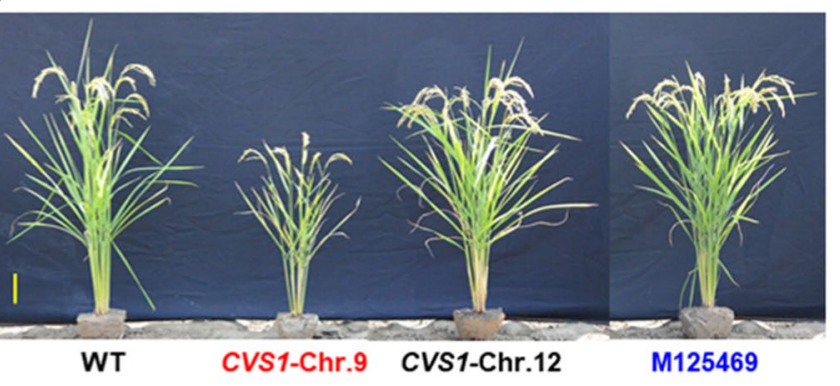

e
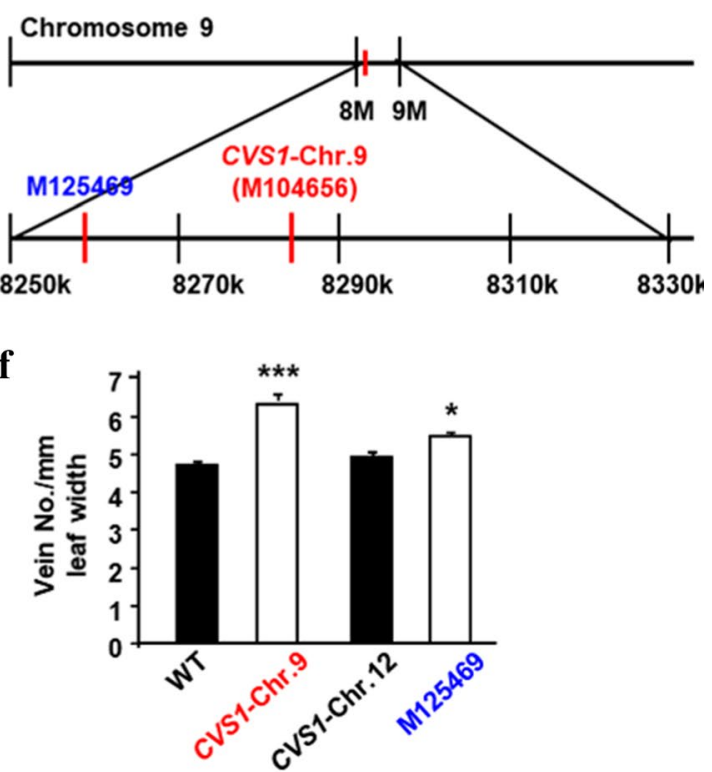

tion site on chromosome 12. d Genotyping and phenotyping of homozygous CVS1-Chr.12. Three primer sets, Chr12-F and Chr12R, T-DNA and Chr12-R, and Chr9-F and Chr9-R, amplified WT and T-DNA-inserted genomic DNA on chromosome 12 and WT genomic DNA of the T-DNA insertion site on chromosome 9. e T-DNA insertion sites of TRIM lines CVS1-Chr.9 (M0104656) and the allelic mutant M0125469 on chromosome 9. f Vein density of segregated CVS1-Chr.9 and CVS1-Chr.12 lines of the $T_{3}$ generation and the allelic mutant M0125469. Values are the average \pm SE of leaves from 10 plants of each line. Scale bar $=10 \mathrm{~cm}$

limited to no yield penalty, thus the negative phenotypes of CVS1 were eliminated (Supplementary Fig. S6). Seedlings and mature plants overexpressing G2-NB-LRR and G7-NB$L R R$ exhibited normal shoot and root growth, plant height, leaf width and leaf color in contrast to the semidwarf and narrow leaf phenotype in CVS1 (Fig. 7b, c, Table 4). This study demonstrated that overexpression of two NB-LRRs increases VD without affecting plant growth from seedling to mature stages. As the seedlings of $G 2-N B-L R R$ and $G 7-N B$ - $L R R$-overexpressing lines exhibited the highest 
Fig. 6 Expression of several genes flanking T-DNA is activated in CVS1. a Position of genes flanking T-DNA in CVS1. The T-DNA was inserted in chromosome 9 at 8,282,951 bp in CVS1. G1-G7 indicate genes flanking T-DNA. b Transcript abundance of $G 1-G 7$ in leaves of WT and CSV1 plants of the $T_{6}$ generation and the allelic mutant M0125469. The actin gene was used as an internal control. RNA samples were extracted from the 1st fully expanded leaf of two independent plants 80 days after imbibition. The right panel shows the diagram of cDNA and primer annealing regions for RT-PCR analysis. The red arrows indicate the direction and annealing regions of the primers $\mathbf{a}$

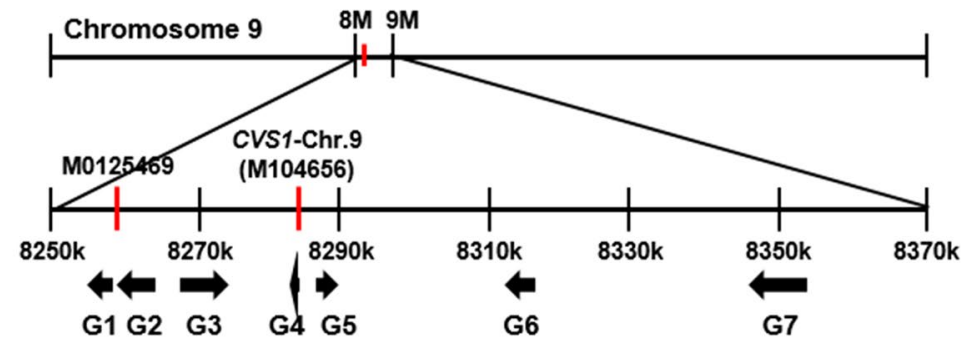

$\mathbf{b}$

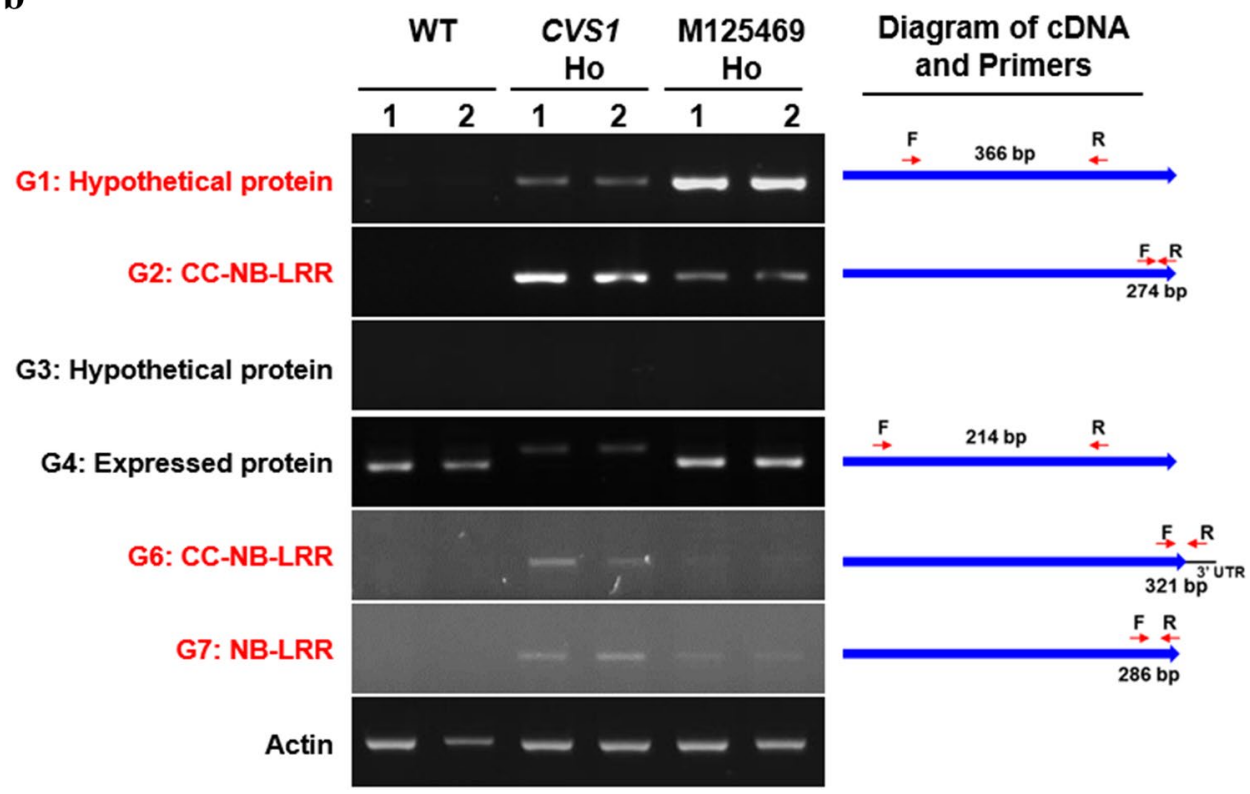

increase in VD, we further characterized the pattern of $\mathrm{M}$ cells and bulliform cells for WT, CVS1, G2-NB-LRR and $G 7-N B-L R R$-overexpressing lines. Reduced interveinal $\mathrm{M}$ cell numbers, $M$ cell length and bulliform cell area were apparent in seedlings of G2-NB-LRR- and G7-NB-LRRoverexpressing lines, similar to those in CVS1 (Fig. 8, Table 4). However, the $\mathrm{M}$ cell size and lobing were normal, which resulted in only a slight reduction in interveinal distances in these transgenic lines compared to WT (Fig. 8b).

\section{NB-LRRs regulating $M$ cell development evolutionarily diverge from other NB-LRRs regulating plant disease resistance}

Phylogenetic analysis of other rice NB-LRR proteins that have been reported to control disease resistance in rice shows that the three G2-, G6- and G7-NB-LRRs are classified into one distinct clade (Fig. 9). G2 and G6 are CC-NB-LRR-type proteins, and G7 is an NB-LRR-type protein (Supplementary Table S5). Amino acids of G2- and G6-NB-LRRs share higher identity and homology of 84 and $91 \%$, respectively, with each other, compared to the identity and homology of 57-58 and
73-74\%, respectively, with G7-NB-LRR (Supplementary Table S6). Surprisingly, G2-, G6- and G7-NB-LRRs share a very low identity and homology of less than 15 and $37 \%$, respectively, with other NB-LRRs (Supplementary Table S6). Amino acid sequence alignment revealed the presence of conserved structural domains, i.e., NB and LRR, in G2-, G6- and G7-NB-LRRs and two other randomly selected rice NB-LRRs known to control disease resistance in rice (Supplementary Fig. S8). We further predicted the expression potential of $G 2$-, G6-, G7-NB-LRRs and six other similar rice $N B-L R R$ genes by GENEVESTIGATOR (v. 8.3.2) (Hruz et al. 2008), the expression potential of G2-, G6-, G7-NB-LRRs is relatively lower than the expression of the other six rice NB-LRRs in all developmental stages and different tissues, suggesting that these three $N B$-LRRs may play unique roles different from the other NB-LRRs. 
Fig. 7 The CVS phenotype is recapitulated by overexpression of $N B-L R R$ in transgenic rice. a Total vein numbers per leaf and vein numbers per $\mathrm{mm}$ leaf width. Values are the average \pm SE of fully expanded leaves of 110-day-old plants. $n=18,17,39,29,40,25$ for WT, $C V S 1$, and transgenic plants overexpressing the flanking genes $G 1, G 2, G 6$ and $G 7$, respectively. b The seedling morphology, leaf color and width of 30-day-old transgenic rice seedlings overexpressing Ubi:G2-NB-LRR and Ubi:G7$N B$ - $L R R$ were similar to the seedling morphology, leaf color and width of the WT. The scale of seedlings and leaves $=3 \mathrm{~cm}$ and $1 \mathrm{~cm}$, respectively. c Mature transgenic rice plants overexpressing $U b i: G 2-N B-L R R$ and Ubi:G7-NB-LRR grew similarly to the WT $\mathbf{a}$

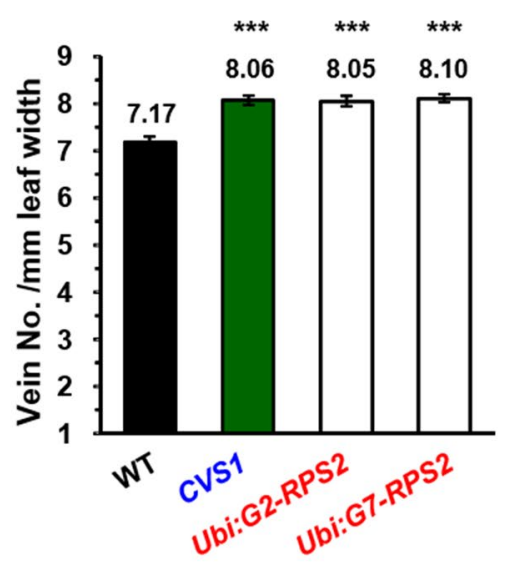

b
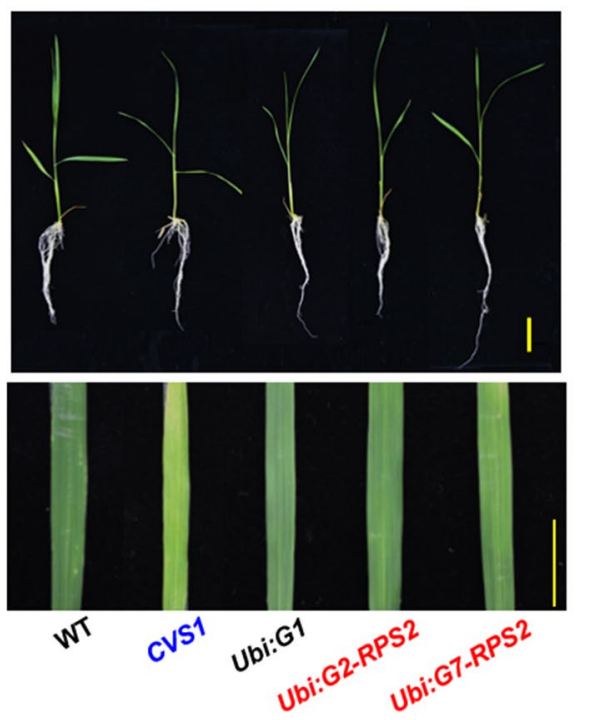

c

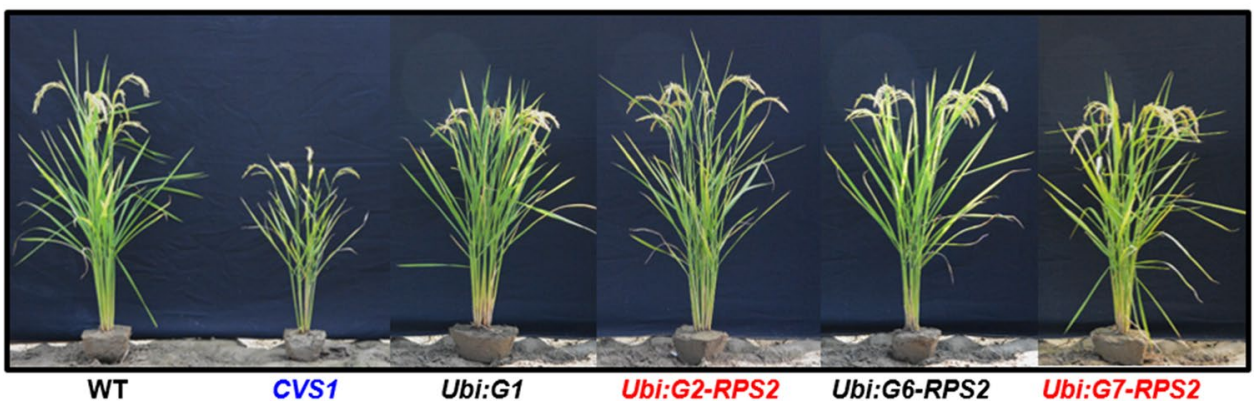

Table 3 Comparison of vein density between WT, G2-NB-LRR, and G7-NB-LRR transgenic plants in different developmental stages

\begin{tabular}{lllllll}
\hline Stage & WT & CVS1 & $G 2-N B-L R R$ & $G 7-N B-L R R$ & $G 2 / \mathrm{WT}(\%)^{\mathrm{a}}$ & $G 7 / \mathrm{WT}(\%)^{\mathrm{a}}$ \\
\hline 34 DAI seedling & $7.17 \pm 0.12$ & $8.06 \pm 0.10^{* * * \mathrm{~b}}$ & $8.05 \pm 0.10^{* * *}$ & $8.10 \pm 0.09 * * *$ & 112 & 113 \\
50 DAI tillering & $4.56 \pm 0.11$ & $6.29 \pm 0.49^{* *}$ & $4.90 \pm 0.15$ & $5.06 \pm 0.14^{*}$ & 107 & 111 \\
73 DAI reproductive & $4.17 \pm 0.06$ & $5.55 \pm 0.12 * * *$ & $4.56 \pm 0.05 * *$ & $4.52 \pm 0.08^{* *}$ & 109 & 108 \\
114 DAI mature & $4.24 \pm 0.03$ & $5.19 \pm 0.08^{* * *}$ & $4.42 \pm 0.04 * * *$ & $4.40 \pm 0.04 * * *$ & 104 & 104 \\
\hline
\end{tabular}

The transgenic plants of G2-NB-LRR and G7-NB-LRR are $T_{3}$ generation. All plants were planted in the 2020-drying season, sample sizes (n) of WT, CVS1, G2-NB-LRR and G7-NB-LRR were 12, 12, 24, 24 for 34 DAI; 5, 4, 8, 9 for 50 DAI; 13, 14, 19, 21 for 73 DAI; and 24, 24 , 48, 24 for 114 DAI, respectively

$D A I$ days after imbibition

${ }^{\mathrm{a}} G 2 / \mathrm{WT}, G 7 / W T(\%)$ : WT was set as $100 \%$, and the impact of $G 2-N B-L R R$ and $G 7-N B-L R R$ were calculated relative to this value

${ }^{\mathrm{b}}$ Values are the means \pm SE. Significance levels were determined with the $t$ test: $* P<0.05, * * P<0.01, * * * P<0.001$

\section{Discussion}

\section{Genetic plasticity of VD is revalidated in rice}

The highly efficient carbon fixation in leaves of $\mathrm{C}_{4}$ grasses relies partly on the combined anatomy of close vein spacing and functionally distinct photosynthetic cell types (Kumar and Kellogg 2019). Consequently, the increased $\mathrm{VD}$ is one of the key factors laying the foundation of $\mathrm{C}_{4}$ anatomy in rice (Feldman, et al. 2014; Kajala et al. 2011; Langdale 2011). In rice, an increase in VD can be achieved by increasing vein number with no alteration in leaf width or by reducing $\mathrm{M}$ cell number to bring the BS cells surrounding two adjacent veins closer. In the present study, the VD of the TRIM mutant population ranged between 2.5 and 10 veins per mm leaf width. This result is significantly different from the result of WT TNG67, which consistently has a VD range between 4 and 6 veins per mm leaf width (Fig. 1). Heritable changes in VD in the TRIM 
Table 4 Comparison of leaf anatomy between WT and G2-NB-LRR and G7-NB-LRR transgenic plants at the seedling stage

\begin{tabular}{|c|c|c|c|c|c|c|c|}
\hline Parameter of $34 \mathrm{DAI}$ (seedlings) & Unit & WT & CVS1 & $G 2-N B-L R R$ & G7-NB-LRR & G2/WT (\%) & $G 7 / W T(\%)$ \\
\hline Leaf width & $\mathrm{mm}$ & $3.16 \pm 0.05$ & $2.77 \pm 0.06^{* *}$ & $3.01 \pm 0.88$ & $3.03 \pm 0.06$ & 95 & 96 \\
\hline Interveinal distance & $\mu \mathrm{m}$ & $164.50 \pm 4.82$ & $118.00 \pm 6.53 * *$ & $124.62 \pm 3.9 * * *$ & $130.20 \pm 3.72 * * *$ & 76 & 79 \\
\hline Interveinal $\mathrm{M}$ cell no & count & $6.32 \pm 0.17$ & $6.13 \pm 0.12$ & $5.16 \pm 0.15 * * *$ & $5.56 \pm 0.21^{*}$ & 82 & 88 \\
\hline M cell length & $\mu \mathrm{m}$ & $30.83 \pm 1.06$ & $20.30 \pm 0.78^{* * *}$ & $25.90 \pm 0.5 * * *$ & $23.56 \pm 0.54 * * *$ & 84 & 76 \\
\hline Bulliform cell area & $\mu \mathrm{m}^{2}$ & $3744.4 \pm 183.7$ & $2481.7 \pm 88.2 * * *$ & $3009.9 \pm 143.2 * * *$ & $2772 \pm 152.1^{* *}$ & 80 & 74 \\
\hline
\end{tabular}

G2/WT, G7/WT (\%): WT was set as 100\%, and the impact of G2-NB-LRR and G7-NB-LRR were calculated relative to this value Values are the means \pm SE. Significance levels were determined with the $t$ test: $* P<0.05, * * P<0.01, * * * P<0.001$

The sample sizes ( $n$ ) of WT, CVS1, G2-NB-LRR and G7-NB-LRR were 12, 12, 24, and 24 for vein density; 17, 13, 34, and 34 for interveinal distance; 43, 38, 32, and 34 for M cell no.; 53, 69, 108, and 105 for $M$ cell length; and 9, 13, 15, and 15 for bulliform cell size, respectively

DAI days after imbibition

Fig. 8 Transgenic plants overexpressing putative RPS2 genes possess reduced interveinal spacing and $\mathrm{M}$ cell numbers. a Light micrographs illustrate transverse sections of leaf tissues of WT, $C V S 1$ ( $T_{2}$ generation) and transgenic rice carrying Ubi:G2-NB-LRR and Ubi:G7-NB-LRR. Numbers of $M$ cells between two veins are labeled. SV: small vein, LV: large vein, BC: bulliform cells. Scale bar $=50 \mu \mathrm{m}$. $\mathrm{b}$ Interveinal spacing and $\mathrm{M}$ cell numbers were determined from the first fully expanded leaves of 20-dayold seedlings. $n=20,19,14,29$ for WT, $C V S 1$ and transgenic plants carrying $U b i: G 2-N B$ $L R R$ and $U b i: G 7-N B-L R R$, respectively $\mathbf{a}$
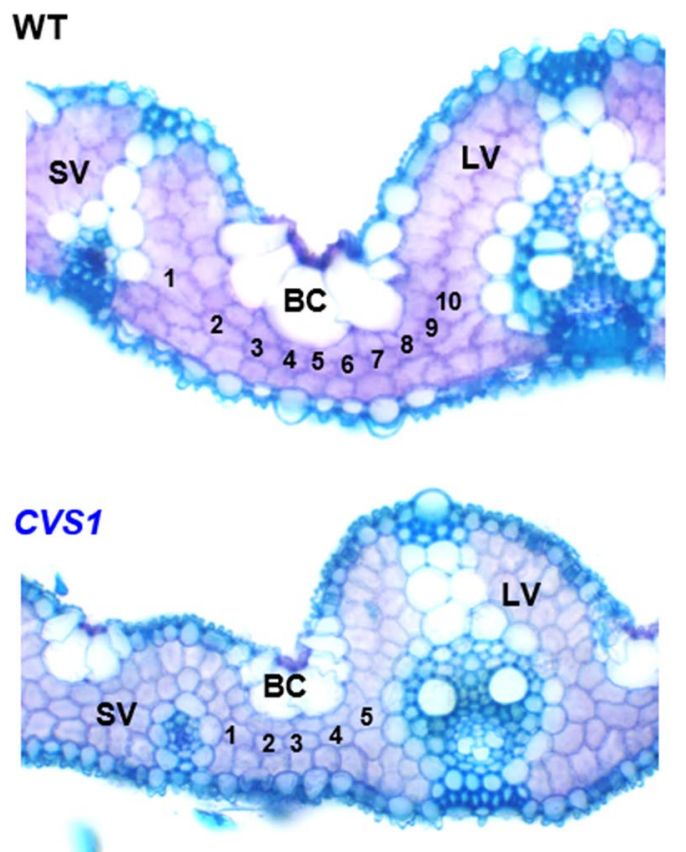

Ubi:G2-NB-LRR

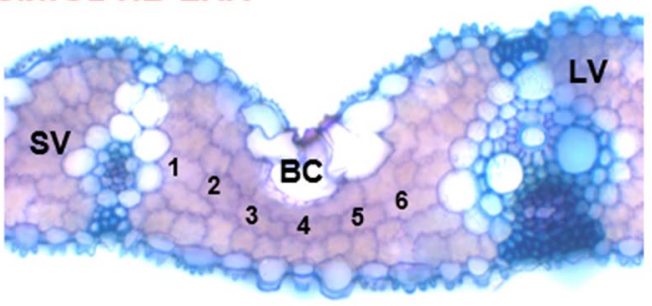

Ubi:G7-NB-LRR

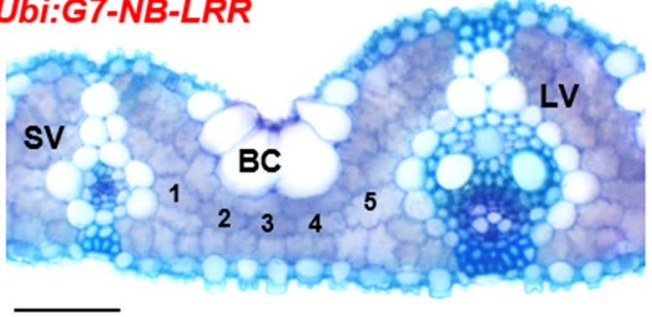

b
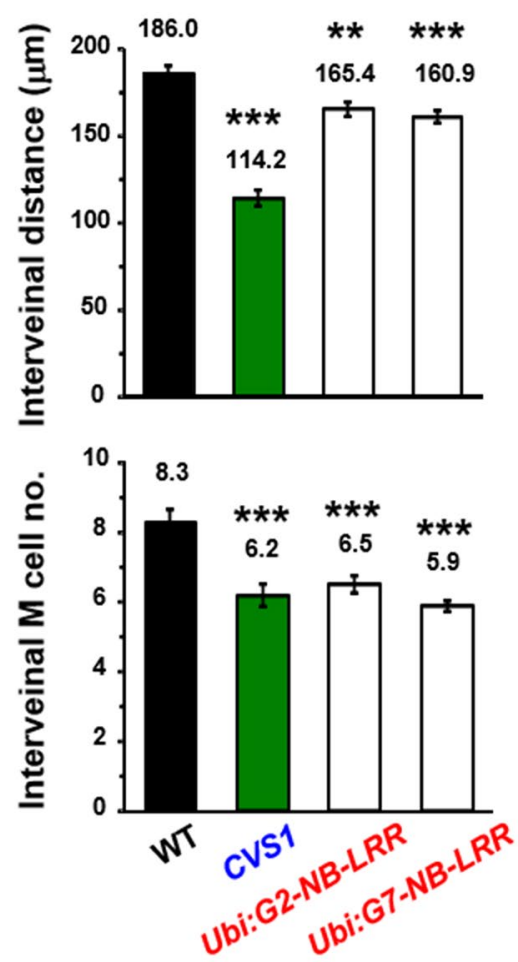
Fig. 9 Phylogenetic analysis of NB-LRRs proteins in plants. a Phylogenetic analysis of 28 NB-LRRs from different plant species. The optimal tree with the sum of branch length $=17.06540678$ is shown. b Phylogenetic analysis of 15 NB-LRRs from rice. The optimal tree with the sum of branch length $=10.33422275$ is shown. Trees are drawn to scale, with branch lengths in the same units as the units of the evolutionary distances used to infer the phylogenetic tree. All ambiguous positions were removed for each sequence pair (pairwise deletion option). There were a total of 2044 positions in the final dataset. The scale value of 0.2 indicates 0.2 amino acid substitutions per site. The yellow background highlights the clade harboring G2-, G6- and G7-NB-LRR

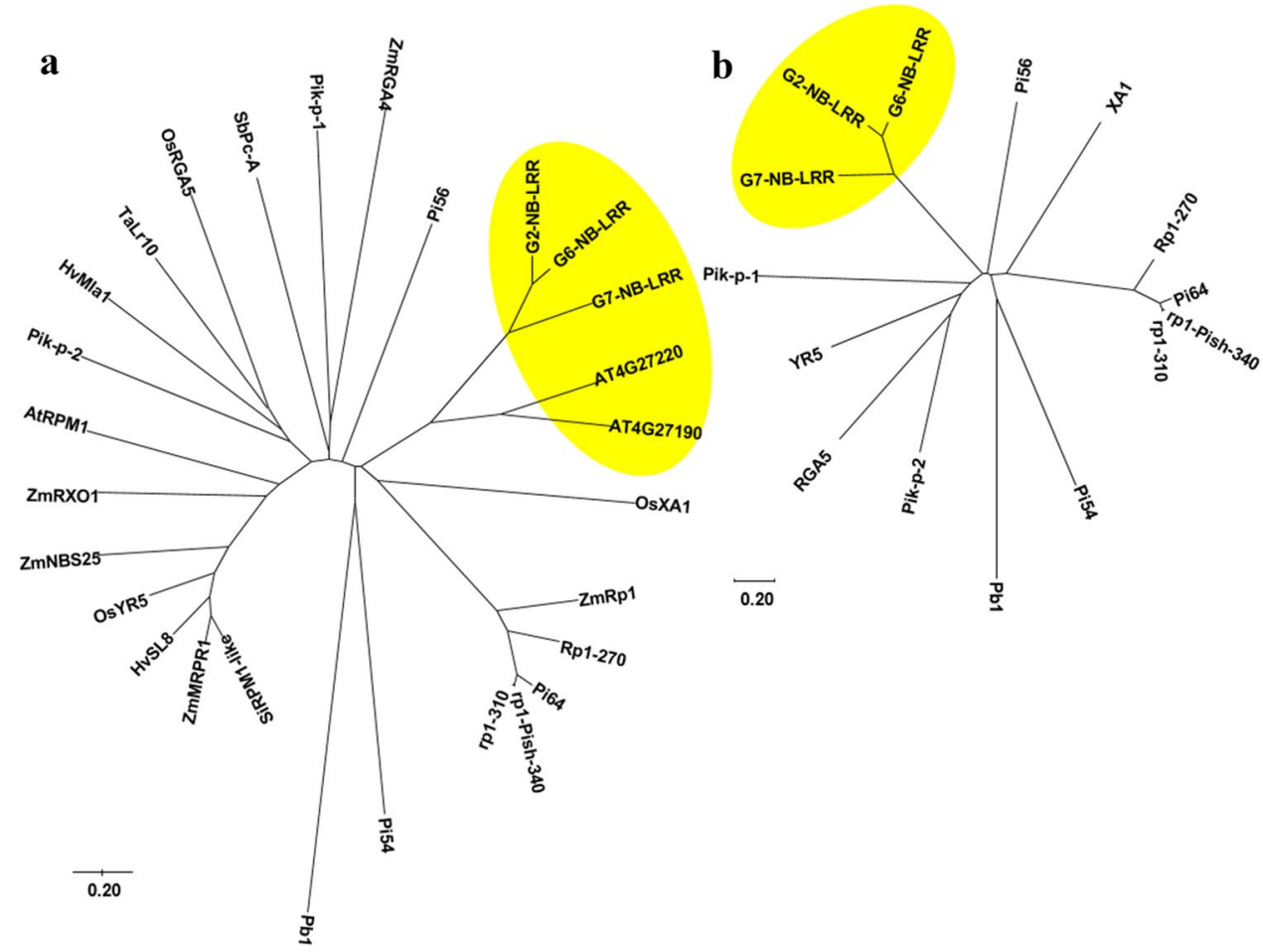

population revalidated the genetic control of this trait in rice, as has been proposed (Feldman et al. 2014). However, a high number (53\%) of apparently false-positive candidates indicated environmental control over vein development (Sack and Scoffoni 2013). The CVS phenotype identified in $\sim 47 \%$ of mutant lines was associated with seed sterility or lethality, which made it difficult to screen for more mutants for the identification of genes regulating VD and related anatomical traits (Supplementary Table S3). Fortunately, CVS1 showed a stably inherited increase in 2-3 veins per mm leaf width over WT, which clearly indicated that VD can be increased in rice (Fig. 2a, Table 1). CVS1 provides a foundation to study aberrations in $\mathrm{M}$ cell structure in rice. Despite having negatively impacted traits such as leaf width, photosynthesis and growth, which appear similar to those in other rice VD mutants identified earlier (Smillie et al. 2012), CVS1 plants were viable and produced seeds.

CVS in rice is a primary requirement for introducing Kranz anatomy in the leaf. To date, a few genes regulating leaf width and leaf rolling have been reported (Guo et al. 2019; Li et al. 2010; Qi et al. 2008; Schuler et al. 2018; Wang et al. 2016a, b), but no genes able to regulate VD without affecting yield have been identified in rice (Schuler et al. 2018; Sims et al. 2021). A leaf VD screen of the TRIM population was originally undertaken to understand genetic plasticity and identify genes regulating vein spacing development in $\mathrm{C}_{3}$ and $\mathrm{C}_{4}$ plants (Feldman et al. 2014; Luo et al. 2018). In the present study, we identified the CVS1 mutant exhibiting a CVS phenotype with a gain-of-function $\mathrm{C}_{4}$-like leaf anatomy. Anatomical examination of $\mathrm{M}$ cells revealed that both reduced cell expansion and cell division account for the CVS phenotype in CVS1.

\section{High VD is associated with reduced interveinal M cell size and number in CVS1}

A key feature of $\mathrm{C}_{4}$ leaf anatomy is an increased ratio of veinal to interveinal regions (Dengler et al. 1994; Muhaidat et al. 2007). CVS1 showed a $35 \%$ increase in VD, because the interveinal space was reduced by $\sim 32 \%$, and an average reduction in individual $\mathrm{M}$ cell length by $\sim 26 \%$ (Table 1 ). In a typical $\mathrm{C}_{4}$ leaf, veins are separated by $2-3 \mathrm{M}$ cells compared to up to $\sim 9 \mathrm{M}$ cells in $\mathrm{C}_{3}$ leaves (Sheehy et al. 2008). Therefore, an 'ideal' rice mutant with Kranz-like internal leaf architecture would possess a significantly reduced internal $\mathrm{M}$ cell number. In the beginning of this study, we hypothesized that activation of gene expression could lead to changes in $\mathrm{M}$ cell number, a basis for the identification of VD mutants through the simple screening of a large mutant population. We found that $C V S 1$ shows a CVS phenotype due to a reduction in both $\mathrm{M}$ cell size and number (Figs. 3 and 8 ). Suggesting that both cell division and lateral $\mathrm{M}$ cell expansion have been affected in the mutant, in contrast to a study in which screening of a gene-deleted IR64 rice mutant population showed altered VD resulting from changes in M cell size rather than $M$ cell number (Smillie et al. 2012), 
indicating that $\mathrm{M}$ cell development is under complex genetic control.

\section{Reduced $M$ cell lobing and chloroplasts impair photosynthesis in CVS1}

$\mathrm{M}$ cell lobing is a special characteristic of the chlorenchyma structure of rice and related warm-climate $\mathrm{C}_{3}$ grasses and has been implicated in refixation of the carbon that is lost during photorespiration in leaf tissues (Sage and Sage 2009). The presence of these specialized anatomical features is associated with high mesophyll conductance (Flexas et al. 2008; von Caemmerer et al. 2012a, b) and photosynthetic activity (Giuliani et al. 2013). The periphery of M cells with deep lobing is usually covered by chloroplasts and stromules to increase the cellular surface exposed to the intercellular airspace and maximize diffusive $\mathrm{CO}_{2}$ conductance and light transmission into the chloroplast stroma in rice (Giuliani et al. 2013; Sage and Sage 2009). Reduction of lobes, chloroplast number within $\mathrm{M}$ cells, and $\mathrm{M}$ cell size (Fig. 3) indicates a significant defectiveness in the coordinated development of chlorenchyma structure in CVS1. As a consequence, a reduction in the degree of $\mathrm{M}$ cell lobing was associated with reduced $g_{m}$ and $A$, which resulted from a reduction in $\mathrm{CO}_{2}$ concentration within the intercellular air space and chloroplasts in CVSI (Fig. 4 and Table 2).

\section{NB-LRR proteins regulate $M$ cell development in rice leaves}

In the CVS1 mutant, the multimerized CaMV $35 S$ enhancers on the T-DNA led to the enhanced expression of three genes encoding $N B-L R R$ and other genes of unknown functions. The three $N B$-LRR genes (G2, G6 and G7) are present in a cluster on chromosome 9 and are activated to different extents by the T-DNA inserted in CVSI (Fig. 6). Transgenic rice overexpressing an Arabidopsis $N B-L R R$ gene, RPS2, exhibits a semidwarf habit, fewer tillers per plant, and lower seed setting rate phenotypes ( $\mathrm{Li}$ et al. 2019), which are similar to these seed setting rate phenotypes found in CVS1 (Fig. 7c). Elevated accumulations of $\mathrm{H}_{2} \mathrm{O}_{2}$ and callose deposition are considered fitness costs for maintaining broad-spectrum resistance against pathogens and pests in transgenic rice overexpressing Arabidopsis RPS2 (Li et al. 2019). However, in the present study, transgenic rice overexpressing the individual rice $N B-L R R$ gene grew normally and limited to no yield penalty (Fig. 7b, c, Supplementary Fig. S6). It is unknown whether these rice $N B-L R R$ genes have similar functions to Arabidopsis RPS2 for conferring disease resistance. Interestingly, we found that only the overexpression of G2-NB-LRR or G7-NB-LRR led to an increased VD phenotype (Fig. 7a, Tables 3,4), indicating that the regulation of vein development and plant growth is genetically separable. Auxin transporters play a crucial role in controlling vein development by auxin transport pathways (Sawchuk et al. 2013). The importance of auxin levels and polar transport in VD has been thoroughly discussed (Huang et al. 2017; Jiajia et al. 2020; Kumar and Kellogg 2019; Wang et al. 2017). Recently, the VD of G2-NB-LRR or G7-NB$L R R$ transgenic plants was found to increase significantly in the seedling stage, and the increase in VD decreased when the plants entered the reproductive stage (Table 3), consistent with the level of endogenous IAA, which is synthesized mainly in immature and meristematic tissues (Kasahara 2016; Leyser 2006). In most reports, auxin was classified as a negative regulator of innate immunity (Singh et al. 2018; Yang et al. 2013). A recent report showed that NB-LRR proteins activate multiple transcription factors via the regulation of auxin, JA and ET plant hormones to switch on defense responses under pattern-triggered immunity (PTI). NB-LRR proteins are the largest gene family and play pleiotropic roles in plants, such as cell growth, differentiation, signaling, and biotic and abiotic stress defense (Li et al. 2017; Meteignier et al. 2016; Uchida et al. 2011; Uchida and Tasaka 2011; Yang et al. 2010). The expression potentials of G2- and $G 7-N B-L R R s$ are also different from the expression potentials of other $N B-L R R$ genes at all developmental stages (Fig. S9), indicating G2- and G7-NB-LRRs may have unique roles in rice. It is worthwhile to further study whether these $G 2$ and G7-NB-LRRs have any functional link to the auxin signaling network.

Although overexpression of G2-NB-LRR or G7-NB-LRR increased VD in transgenic rice, the extent of the increase was much lower than the extent of the increase in CVSI (Supplementary Fig. S7e). One possibility is that overexpression of multiple genes that have been activated in the cluster on chromosome 9 is required for a significant increase in VD. This notion is supported by a study showing that constitutive overexpression of 60 known developmental regulators from maize individually did not confer an increased VD phenotype in transgenic rice (Wang et al. 2017). Alternatively, the leaf width and the interveinal distance were reduced by 37 and $32-34 \%$, respectively, in CVSI compared with these leaf width and the interveinal distance in WT (Table 1, Fig. 8b), suggesting that a combination of the reduced leaf width and interveinal distance contributes to the significantly higher VD in CVS1. The chlorophyll content of transgenic rice overexpressing G2-NB-LRR and $G 7-N B-L R R$ is also slightly higher, but there is no significant difference in photosynthetic rate, which indicates that further introduction of $\mathrm{C}_{4}$ genes into transgenic rice with anatomical changes is necessary for functional $\mathrm{C}_{4}$ like rice creation (Ermakova et al. 2020; Sen et al. 2017). Studies with gene loss-of-function mutagenesis have identified numerous mutants with alterations in leaf anatomy associated with pleiotropic phenotypes (Fladung 1994; Rizal et al. 
2015), suggesting that the establishment of $\mathrm{C}_{4}$ leaf anatomy is regulated by a complex regulatory network. Nevertheless, we found that the number but not the size of interveinal $\mathrm{M}$ cells was significantly reduced in the leaves of $G 2-N B$ $L R R$ and $G 7-N B-L R R$ transgenic rice plants, revealing an important factor controlling the interveinal distance in rice (Fig. 8, Table 4).

\section{Bulliform cell size also contributes to the CVS phenotype}

The significant reduction in interveinal distance in CVS1 also resulted from a combination of several internal morphological changes, including a reduction in $\mathrm{M}$ cell size and number and bulliform cell size (Fig. 8, Table 4). Bulliform cells are large, bubble-shaped epidermal cells that are present in groups on the adaxial surfaces of leaves in grasses. These cells are essential for water storage and are involved in the rolling of leaves to avoid water loss through transpiration under severe drought and salinity conditions (Grigore and Toma 2017). Loss of function of the narrow leaf 7 (NAL7) gene, which controls auxin biosynthesis, results in reduced bulliform cell size and number and leaf width and slightly reduced interveinal distance, but not other phenotypes, in rice (Fujino et al. 2008). Supporting the notion that the phenotype of narrow leaves and reduced interveinal distance in $C V S 1$ could be related to bulliform cell size. $C V S 1$ and $G 2-N B-L R R$ and $G 7-N B$ $L R R$ transgenic rice exhibited increased VD and shortened interveinal distance by sharing altered phenotypes of reduced $\mathrm{M}$ cell and bulliform cell sizes. However, reduced lobing in smaller M cells was not detected in the G2-NB$L R R$ and $G 7-N B-L R R$ transgenic lines, indicating that the development of lobing is likely associated with $\mathrm{M}$ cell development. It is unclear whether the narrow leaf width along with the semidwarf plant architecture found in CVSI are regulated by multiple genes flanking the T-DNA or by somatic mutation linked to the T-DNA insertion.

Supplementary Information The online version contains supplementary material available at https://doi.org/10.1007/s00299-021-02810-5.

Acknowledgements The authors thank Irma Canicosa, Jaylord Alcachupas and Nelson Alcones (International Rice Research Institute) for assistance with gas exchange measurements, Hsiang-Chun Lin for transgenic plant management and Kristel Mae Perdigon for transcript analysis, Su-May Yu's laboratory for rice transformation, and Su-May $\mathrm{Yu}$ and Tuan-Hua David Ho for serving as advisors for all research work and manuscript writing. We also acknowledge the financial support of the Bill and Melinda Gates Foundation-funded $\mathrm{C}_{4}$ rice program and IRRI and the contributions of the associated international consortium members. This work was also supported by Grants from the Ministry of Science and Technology (MOST 104-2321-B-001-054, MOST 105-2321-B-001-035 and MOST 106-2321-B-001-023) and in part by the Advanced Plant Biotechnology Center from the Featured Areas Research Center Program within the framework of the
Higher Education Sprout Project by the Ministry of Education (MOE) in Taiwan.

Author contribution statement $\mathrm{AKB}, \mathrm{RN}$ and JC performed the VD screening. JC, AEM, and RN performed microscopy and gas exchange measurements. YIH provided information of TRIM database. SFLo, ILL, PJC, and YPC carried out mutant genotyping, molecular analysis of the mutants and transgenic plants, and transgenic plant characterization. SFLo surveyed the NB-LRRs from the rice genome and performed phylogenetic tree analysis. SFLo provided bioinformatics support to the team. SFLo supervised mutant genotyping, molecular biology analyses and transgenic plant characterization. SFLo, JC, and AKB interpreted the data and wrote the manuscript. WPQ and AB supervised the screening work at IRRI.

\section{Declarations}

Conflict of interest We declare that we have no conflicts of interest related to this work, this paper has not been published previously and it is not been submitted to any other journal for review.

Open Access This article is licensed under a Creative Commons Attribution 4.0 International License, which permits use, sharing, adaptation, distribution and reproduction in any medium or format, as long as you give appropriate credit to the original author(s) and the source, provide a link to the Creative Commons licence, and indicate if changes were made. The images or other third party material in this article are included in the article's Creative Commons licence, unless indicated otherwise in a credit line to the material. If material is not included in the article's Creative Commons licence and your intended use is not permitted by statutory regulation or exceeds the permitted use, you will need to obtain permission directly from the copyright holder. To view a copy of this licence, visit http://creativecommons.org/licenses/by/4.0/.

\section{References}

Bruce WB, Christensen AH, Klein T, Fromm M, Quail PH (1989) Photoregulation of a phytochrome gene promoter from oat transferred into rice by particle bombardment. Proc Natl Acad Sci USA 86:9692-9696

Chatterjee J, Dionora J, Elmido-Mabilangan A, Wanchana S, Thakur V, Bandyopadhyay A, Brar DS, Quick WP (2016) The evolutionary basis of naturally diverse rice leaves anatomy. PLoS ONE 11:e0164532

Chen P-W, Lu C-A, Yu T-S, Tseng T-H, Wang C-S, Yu S-M (2002) Rice $\alpha$-amylase transcriptional enhancers direct multiple mode regulation of promoters in transgenic rice*. J Biol Chem 277:13641-13649

Clayton H, Saladie M, Rolland V, Sharwood R, Macfarlane T, Ludwig M (2017) Loss of the chloroplast transit peptide from an ancestral C3 carbonic anhydrase is associated with C4 evolution in the grass genus neurachne. Plant Physiol 173:1648-1658

Dangl JL, Jones JD (2001) Plant pathogens and integrated defence responses to infection. Nature 411:826-833

Dengler NG, Dengler RE, Donnelly PM, Hattersley PW (1994) Quantitative leaf anatomy of $\mathrm{C} 3$ and $\mathrm{C} 4$ grasses (poaceae): bundle sheath and mesophyll surface area relationships. Ann Bot 73:241-255

Doyle JJ (1987) A rapid DNA isolation procedure for small quantities of fresh leaf tissue. Phytochem Bull 19:11-15

Ermakova M, Danila FR, Furbank RT, von Caemmerer S (2020) On the road to C4 rice: advances and perspectives. Plant J 101:940-950 
Farquhar G, Wong S (1984) An empirical model of stomatal conductance. Funct Plant Biol 11:191-210

Feldman AB, Murchie EH, Leung H, Baraoidan M, Coe R, Yu S-M, Lo S-F, Quick WP (2014) Increasing leaf vein density by mutagenesis: laying the foundations for C4 rice. PLoS ONE 9:e94947

Feldman AB, Leung H, Baraoidan M, Elmido-Mabilangan A, Canicosa I, Quick WP, Sheehy J, Murchie EH (2017) Increasing leaf vein density via mutagenesis in rice results in an enhanced rate of photosynthesis, smaller cell sizes and can reduce interveinal mesophyll cell number. Front Plant Sci 8:1883

Fladung M (1994) Genetic variants of panicum maximum (Jacq.) in C4 photosynthetic traits. J Plant Physiol 143:165-172

Flexas J, Ribas-Carbo M, Diaz-Espejo A, Galmes J, Medrano H (2008) Mesophyll conductance to $\mathrm{CO}$ : current knowledge and future prospects. Plant Cell Environ 31:602-621

Fujino K, Matsuda Y, Ozawa K, Nishimura T, Koshiba T, Fraaije MW, Sekiguchi H (2008) NARROW LEAF 7 controls leaf shape mediated by auxin in rice. Mol Genet Genomics 279:499-507

Furbank R, von Caemmerer S, Sheehy J, Edwards G (2009) C4 rice: a challenge for plant phenomics. Funct Plant Biol 36:845-856

Giuliani R, Koteyeva N, Voznesenskaya E, Evans MA, Cousins AB, Edwards GE (2013) Coordination of leaf photosynthesis, transpiration, and structural traits in rice and wild relatives (Genus Oryza). Plant Physiol 162:1632-1651

Grigore M-N, Toma C (2017) Bulliform cells. Anatomical adaptations of halophytes: a review of classic literature and recent findings. Springer International Publishing, Cham, pp 325-338

Guo T, Wang D, Fang J, Zhao J, Yuan S, Xiao L, Li X (2019) Mutations in the rice OsCHR4 gene, encoding a CHD3 family chromatin remodeler, induce narrow and rolled leaves with increased cuticular wax. Int J Mol Sci 20:2567

Hajdukiewicz P, Svab Z, Maliga P (1994) The small, versatile pPZP family of Agrobacterium binary vectors for plant transformation. Plant Mol Biol 25:989-994

Hibberd J, Sheehy J, Langdale J (2008) Using C4 photosynthesis to increase the yield of rice-rationale and feasibility. Curr Opin Plant Biol 11:228-231

Hruz T, Laule O, Szabo G, Wessendorp F, Bleuler S, Oertle L, Widmayer P, Gruissem W, Zimmermann P (2008) Genevestigator V3: a reference expression database for the meta-analysis of transcriptomes. Adv Bioinform 2008:420747

Hsing Y-I, Chern C-G, Fan M-J, Lu P-C, Chen K-T, Lo S-F, Sun P-K, Ho S-L, Lee K-W, Wang Y-C, Huang W-L, Ko S-S, Chen S, Chen J-L, Chung C-I, Lin Y-C, Hour A-L, Wang Y-W, Chang Y-C, Tsai M-W, Lin Y-S, Chen Y-C, Yen H-M, Li C-P, Wey C-K, Tseng C-S, Lai M-H, Huang S-C, Chen L-J, Yu S-M (2007) A rice gene activation/knockout mutant resource for high throughput functional genomics. Plant Mol Biol 63:351-364

Huang CF, Yu CP, Wu YH, Lu MJ, Tu SL, Wu SH, Shiu SH, Ku MSB, Li WH (2017) Elevated auxin biosynthesis and transport underlie high vein density in $\mathrm{C} 4$ leaves. Proc Natl Acad Sci U S A 114:E6884-E6891

Jiajia W, Jing X, Qian Q, Guangheng Z (2020) Development of rice leaves: how histocytes modulate leaf polarity establishment. Rice Sci 27:468-479

Kajala K, Covshoff S, Karki S, Woodfield H, Tolley BJ, Dionora MJA, Mogul RT, Mabilangan AE, Danila FR, Hibberd JM, Quick WP (2011) Strategies for engineering a two-celled C4 photosynthetic pathway into rice. J Exp Bot 62:3001-3010

Kasahara H (2016) Current aspects of auxin biosynthesis in plants. Biosci Biotechnol Biochem 80:34-42

Kawahara Y, de la Bastide M, Hamilton JP, Kanamori H, McCombie WR, Ouyang S, Schwartz DC, Tanaka T, Wu J, Zhou S, Childs KL, Davidson RM, Lin H, Quesada-Ocampo L, Vaillancourt B, Sakai H, Lee SS, Kim J, Numa H, Itoh T, Buell CR, Matsumoto T (2013) Improvement of the Oryza sativa Nipponbare reference genome using next generation sequence and optical map data. Rice 6:4

Kumar D, Kellogg EA (2019) Getting closer: vein density in C4 leaves. New Phytol 221:1260-1267

Kumar S, Stecher G, Li M, Knyaz C, Tamura K (2018) MEGA X: molecular evolutionary genetics analysis across computing platforms. Mol Biol Evol 35:1547-1549

Langdale JA (2011) C4 cycles: past, present, and future research on C4 photosynthesis. Plant Cell 23:3879-3892

Langdale JA, Nelson T (1991) Spatial regulation of photosynthetic development in C4 plants. Trends Genet TIG 7:191-196

Leyser O (2006) Dynamic integration of auxin transport and signalling. Curr Biol CB 16:R424-433

Li L, Shi ZY, Li L, Shen GZ, Wang XQ, An LS, Zhang JL (2010) Overexpression of ACL1 (abaxially curled leaf 1) increased Bulliform cells and induced Abaxial curling of leaf blades in rice. Mol Plant 3:807-817

Li X, Zhang Y, Yin L, Lu J (2017) Overexpression of pathogeninduced grapevine TIR-NB-LRR gene VaRGA1 enhances disease resistance and drought and salt tolerance in Nicotiana benthamiana. Protoplasma 254:957-969

Li Z, Huang J, Wang Z, Meng F, Zhang S, Wu X, Zhang Z, Gao Z (2019) Overexpression of Arabidopsis nucleotide-binding and leucine-rich repeat genes RPS2 and RPM1 (D505V) confers broad-spectrum disease resistance in rice. Front Plant Sci 10:417

Linh NM, Verna C, Scarpella E (2018) Coordination of cell polarity and the patterning of leaf vein networks. Curr Opin Plant Biol 41:116-124

Lo SF, Yang SY, Chen KT, Hsing YI, Zeevaart JA, Chen LJ, Yu SM (2008) A novel class of gibberellin 2-oxidases control semidwarfism, tillering, and root development in rice. Plant Cell 20:2603-2618

Lo SF, Fan MJ, Hsing YI, Chen LJ, Chen S, Wen IC, Liu YL, Chen KT, Jiang MJ, Lin MK, Rao MY, Yu LC, Ho TH, Yu SM (2016) Genetic resources offer efficient tools for rice functional genomics research. Plant Cell Environ 39:998-1013

Lundgren MR, Osborne CP, Christin P-A (2014) Deconstructing Kranz anatomy to understand C4 evolution. J Exp Bot 65:3357-3369

Luo M, Zhang S, Tang C, Jia G, Tang S, Zhi H, Diao X (2018) Screening of mutants related to the $\mathrm{C} 4$ photosynthetic Kranz structure in foxtail millet. Front Plant Sci 9:1650

Lux A, Morita S, Abe J, Ito K (2005) An improved method for clearing and staining free-hand sections and whole-mount samples. Ann Bot 96:989-996

Ma J, Lei C, Xu X, Hao K, Wang J, Cheng Z, Ma X, Ma J, Zhou K, Zhang X, Guo X, Wu F, Lin Q, Wang C, Zhai H, Wang H, Wan J (2015) Pi64, encoding a novel CC-NBS-LRR protein, confers resistance to leaf and neck blast in rice. Mol Plant Microbe Interact 28:558-568

McKown AD, Dengler NG (2007) Key innovations in the evolution of Kranz anatomy and C4 vein pattern in Flaveria (Asteraceae). Am J Bot 94:382-399

Meteignier LV, Zhou J, Cohen M, Bhattacharjee S, Brosseau C, Chan MG, Robatzek S, Moffett P (2016) NB-LRR signaling induces translational repression of viral transcripts and the formation of RNA processing bodies through mechanisms differing from those activated by UV stress and RNAi. J Exp Bot 67:2353-2366

Muhaidat R, Sage RF, Dengler NG (2007) Diversity of Kranz anatomy and biochemistry in C4 eudicots. Am J Bot 94:362-381

Murashige T, Skoog F (1962) A revised medium for rapid growth and bio assays with tobacco tissue cultures. Physiol Plant 15:473-497 
Peng R, Zhang B (2021) Foxtail millet: a new model for C4 plants. Trends Plant Sci 26:199-201

Qi J, Qian Q, Bu Q, Li S, Chen Q, Sun J, Liang W, Zhou Y, Chu C, Li X, Ren F, Palme K, Zhao B, Chen J, Chen M, Li C (2008) Mutation of the rice Narrow leafl gene, which encodes a novel protein, affects vein patterning and polar auxin transport. Plant Physiol 147:1947-1959

Rizal G, Thakur V, Dionora J, Karki S, Wanchana S, Acebron K, Larazo N, Garcia R, Mabilangan A, Montecillo F, Danila F, Mogul R, Pablico P, Leung H, Langdale JA, Sheehy J, Kelly S, Quick WP (2015) Two forward genetic screens for vein density mutants in sorghum converge on a cytochrome P450 gene in the brassinosteroid pathway. Plant J 84:257-266

Sack L, Scoffoni C (2013) Leaf venation: structure, function, development, evolution, ecology and applications in the past, present and future. New Phytol 198:983-1000

Sage TL, Sage RF (2009) The functional anatomy of rice leaves: implications for refixation of photorespiratory $\mathrm{CO} 2$ and efforts to engineer C4 photosynthesis into rice. Plant Cell Physiol 50:756-772

Sage RF, Christin PA, Edwards EJ (2011) The C(4) plant lineages of planet earth. J Exp Bot 62:3155-3169

Sage RF, Khoshravesh R, Sage TL (2014) From proto-Kranz to C4 Kranz: building the bridge to $\mathrm{C} 4$ photosynthesis. J Exp Bot 65:3341-3356

Saitou N, Nei M (1987) The neighbor-joining method: a new method for reconstructing phylogenetic trees. Mol Biol Evol 4:406-425

Sawchuk MG, Edgar A, Scarpella E (2013) Patterning of leaf vein networks by convergent auxin transport pathways. PLoS Genet 9:e1003294

Scarpella E, Meijer A (2004) Pattern formation in the vascular system of monocot and dicot plant species. New Phytol 164:209-242

Scarpella E, Rueb S, Meijer AH (2003) The RADICLELESS1 gene is required for vascular pattern formation in rice. Development 130:645-658

Schuler ML, Mantegazza O, Weber APM (2016) Engineering C4 photosynthesis into $\mathrm{C} 3$ chassis in the synthetic biology age. Plant $\mathrm{J}$ 87:51-65

Schuler ML, Sedelnikova OV, Walker BJ, Westhoff P, Langdale JA (2018) SHORTROOT-mediated increase in stomatal density has no impact on photosynthetic efficiency. Plant Physiol 176:757-772

Sedelnikova OV, Hughes TE, Langdale JA (2018) Understanding the genetic basis of C4 Kranz anatomy with a view to engineering C3 crops. Annu Rev Genet 52:249-270

Sen P, Ghosh S, Sarkar S, Chanda P, Mukherjee A, Datta S, Datta K (2017) Pyramiding of three C4 specific genes towards yield enhancement in rice. Plant Cell. Tissue Organ Cult (PCTOC) 128: $145-160$

Sharkey TD, Bernacchi CJ, Farquhar GD, Singsaas EL (2007) Fitting photosynthetic carbon dioxide response curves for $\mathrm{C}(3)$ leaves. Plant Cell Environ 30:1035-1040

Sheehy JE, Mitchell PL, Hardy B (2008) Charting new pathways to C4 rice. World Scientific Publishing Company

Sims K, Abedi-Samakush F, Szulc N, Macias Honti MG, Mattsson J (2021) OsARF11 promotes growth, meristem, seed, and vein formation during rice plant development. Int J Mol Sci 22:4089

Singh PK, Nag A, Arya P, Kapoor R, Singh A, Jaswal R, Sharma TR (2018) Prospects of understanding the molecular biology of disease resistance in rice. Int J Mol Sci 19:1141

Singh J, Gupta SK, Devanna BN, Singh S, Upadhyay A, Sharma TR (2020) Blast resistance gene Pi54 over-expressed in rice to understand its cellular and sub-cellular localization and response to different pathogens. Sci Rep 10:5243

Smillie IR, Pyke KA, Murchie EH (2012) Variation in vein density and mesophyll cell architecture in a rice deletion mutant population. $\mathrm{J}$ Exp Bot 63:4563-4570
Spurr AR (1969) A low-viscosity epoxy resin embedding medium for electron microscopy. J Ultrastruct Res 26:31-43

Takken FL, Goverse A (2012) How to build a pathogen detector: structural basis of NB-LRR function. Curr Opin Plant Biol 15:375-384

Uchida N, Tasaka M (2011) Regulation of NB-LRR-type UNI and its related signaling pathway: signaling crosstalk and methodology for quick identification of related factors. Plant Signal Behav 6:1219-1222

Uchida N, Igari K, Bogenschutz NL, Torii KU, Tasaka M (2011) Arabidopsis ERECTA-family receptor kinases mediate morphological alterations stimulated by activation of NB-LRR-type UNI proteins. Plant Cell Physiol 52:804-814

Upadhyaya NM, Zhou X-R, Zhu Q-H, Ramm K, Wu L, Eamens A, Sivakumar R, Kato T, Yun D-W, Santhoshkumar C, Narayanan KK, Peacock JW, Dennis ES (2002) An $i A c / D s$ gene and enhancer trapping system for insertional mutagenesis in rice. Funct Plant Biol 29:547-559

Vogan PJ, Frohlich MW, Sage RF (2007) The functional significance of C3-C4 intermediate traits in Heliotropium L. (Boraginaceae): gas exchange perspectives. Plant Cell Environ 30:1337-1345

von Caemmerer S, Quick WP, Furbank RT (2012a) The development of $\mathrm{C}_{4}$ rice: current progress and future challenges. Science 336:1671-1672

von Caemmerer S, Quick WP, Furbank RT (2012b) The development of $\mathrm{C} 4$ rice: current progress and future challenges. Science 336:1671-1672

Wang Q, Zhang Q, Fan D, Lu C (2006) Photosynthetic light and CO2 utilization and $\mathrm{C} 4$ traits of two novel super-rice hybrids. J Plant Physiol 163:529-537

Wang L, Xu J, Nian J, Shen N, Lai K, Hu J, Zeng D, Ge C, Fang Y, Zhu L, Qian Q, Zhang G (2016a) Characterization and fine mapping of the rice gene OsARVL4 regulating leaf morphology and leaf vein development. Plant Growth Regul 78:345-356

Wang P, Vlad D, Langdale JA (2016b) Finding the genes to build C4 rice. Curr Opin Plant Biol 31:44-50

Wang P, Karki S, Biswal AK, Lin H-C, Dionora MJ, Rizal G, Yin X, Schuler ML, Hughes T, Fouracre JP, Jamous BA, Sedelnikova O, Lo S-F, Bandyopadhyay A, Yu S-M, Kelly S, Quick WP, Langdale JA (2017) Candidate regulators of early leaf development in maize perturb hormone signalling and secondary cell wall formation when constitutively expressed in rice. Sci Rep 7:4535

Xu Y, Liu F, Zhu S, Li X (2018) The maize NBS-LRR gene ZmNBS25 enhances disease resistance in rice and Arabidopsis. Front Plant Sci 9:1033

Yang S, Feng Z, Zhang X, Jiang K, Jin X, Hang Y, Chen JQ, Tian D (2006) Genome-wide investigation on the genetic variations of rice disease resistance genes. Plant Mol Biol 62:181-193

Yang H, Shi Y, Liu J, Guo L, Zhang X, Yang S (2010) A mutant CHS3 protein with TIR-NB-LRR-LIM domains modulates growth, cell death and freezing tolerance in a temperature-dependent manner in Arabidopsis. Plant J 63:283-296

Yang D-L, Yang Y, He Z (2013) Roles of plant hormones and their interplay in rice immunity. Mol Plant 6:675-685

Ye Z, Ting JP (2008) NLR, the nucleotide-binding domain leucine-rich repeat containing gene family. Curr Opin Immunol 20:3-9

Zuckerkandl E, Pauling L (1965) Evolutionary divergence and convergence in proteins. In: Bryson V, Vogel HJ (eds) Evolving genes and proteins. Academic Press, New York, pp 97-166

Publisher's Note Springer Nature remains neutral with regard to jurisdictional claims in published maps and institutional affiliations. 